\title{
Wave-Current Interaction between Hurricane Matthew Wave Fields and the Gulf Stream
}

\author{
Christie A. Hegermiller \\ Applied Ocean Physics and Engineering, Woods Hole Oceanographic Institution, Woods Hole, Massachusetts \\ JOHN C. WARNER \\ Woods Hole Coastal and Marine Science Center, U.S. Geological Survey, Woods Hole, Massachusetts \\ MAITANE OLABARRIETA \\ University of Florida, Gainesville, Florida \\ CHRISTOPHER R. SHERWOOD \\ Woods Hole Coastal and Marine Science Center, U.S. Geological Survey, Woods Hole, Massachusetts
}

(Manuscript received 20 May 2019, in final form 26 August 2019)

\begin{abstract}
Hurricanes interact with the Gulf Stream in the South Atlantic Bight (SAB) through a wide variety of processes, which are crucial to understand for prediction of open-ocean and coastal hazards during storms. However, it remains unclear how waves are modified by large-scale ocean currents under storm conditions, when waves are aligned with the storm-driven circulation and tightly coupled to the overlying wind field. Hurricane Matthew (2016) impacted the U.S. Southeast coast, causing extensive coastal change due to large waves and elevated water levels. The hurricane traveled on the continental shelf parallel to the SAB coastline, with the right side of the hurricane directly over the Gulf Stream. Using the Coupled Ocean-AtmosphereWave-Sediment Transport modeling system, we investigate wave-current interaction between Hurricane Matthew and the Gulf Stream. The model simulates ocean currents and waves over a grid encompassing the U.S. East Coast, with varied coupling of the hydrodynamic and wave components to isolate the effect of the currents on the waves, and the effect of the Gulf Stream relative to storm-driven circulation. The Gulf Stream modifies the direction of the storm-driven currents beneath the right side of the hurricane. Waves transitioned from following currents that result in wave lengthening, through negative current gradients that result in wave steepening and dissipation. Wave-current interaction over the Gulf Stream modified maximum coastal total water levels and changed incident wave directions at the coast by up to $20^{\circ}$, with strong implications for the morphodynamic response and stability of the coast to the hurricane.
\end{abstract}

\section{Introduction}

Wave-current interaction has been extensively studied in coastal environments where shoaling waves encounter strong, highly variable tidal and wind-driven currents at inlets and in the surf zone (e.g., Olabarrieta et al. 2014; Orescanin et al. 2014; Zippel and Thomson 2015). Waves are influenced by currents through refraction over gradients in the current velocity, shoaling and breaking over opposing currents, wave lengthening over following currents, and relative wind effects on the

Corresponding author: Christie A. Hegermiller, chegermiller@ whoi.edu momentum flux due to following or opposing winds and waves. In spectral wave models, the first three effects are included in the evolution of the wavenumber and the phase speed of wave action (Ardhuin et al. 2012). The last effect is in the wind input term, in which the wind velocity is simply modified by the underlying current, such that the momentum flux generating wind waves is reduced in following currents and winds. Currents are affected by waves through the excess of momentum flux, implemented as gradients in radiation stress or vortex forces. However, high-velocity currents and large gradients in current velocities, and the complex wave fields that interact with them, are not constrained to the nearshore environment. 
Early idealized, theoretical, and observational studies examined potential refraction and trapping of wave energy over the Gulf Stream and its eddies (e.g., Holthuijsen and Tolman 1991; Kudryavstev et al. 1995; White and Fornberg 1998). Recent work has reemphasized the importance of wave-current interaction over large-scale currents over the global ocean, for example the Agulhas Current, the Leeuwin Current (Wandres et al. 2017), the Antarctic Circumpolar Current (ACC; Rapizo et al. 2018), and the Gulf Stream and related mesoscale eddies (Ardhuin et al. 2017). Warner et al. (2017) invoked wave-current interaction over the Gulf Stream as generating maximum wave heights during Hurricane Sandy (2012). Ardhuin et al. (2017) found that refraction of waves over mesoscale circulation features modulates the wave energy distribution over the global ocean. Rapizo et al. (2018) found that inclusion of the effects of the ACC on modeled global wave fields yields smaller bias of significant wave height compared to satellite altimetry measurements, due to a reduction of the relative wind input over following currents and waves.

Quantification of the interaction of the mean wave field with large-scale currents leads to the natural question of the extent of modification of extreme wave fields by large-scale currents. Fan et al. (2009) examined wave-current interaction between Hurricane Ivan (2004) wave fields and the Loop Current. The authors found that resolution of wave-current interaction improved predictions of bulk wave parameters. Further, Fan et al. (2009) found wider directional spreading of the hurricane wave spectra in the presence of ocean currents. Tropical cyclones regularly interact with western boundary currents, such as the Gulf Stream or Kuroshio, yet studies of wave-current interaction beneath hurricanes has been limited to interaction between waves and storm-driven circulation. Moon et al. (2003) examined wave spectra under Hurricane Bonnie (1998) in the North Atlantic, but did not evaluate the impact of wave-current interaction over the Gulf Stream. Far-field swell generated by approaching hurricanes in the North Atlantic Ocean has been shown to refract over gradients in currents at Gulf Stream walls (Holthuijsen and Tolman 1991; Kudryavstev et al. 1995). The interaction of rapidly evolving wind seas, swells, and storm-driven circulation beneath a hurricane and the Gulf Stream has not been thoroughly investigated.

Most recent studies of wave-current interaction over large-scale ocean currents have focused on the effect of wave-current interaction on bulk wave parameters, such as significant wave height, peak wave period, and peak wave direction. However, under hurricanes, wave spectra can be highly bimodal and poorly characterized by bulk wave parameters (Young 2003; Collins et al. 2018). Hurricane wave spectra rapidly evolve and vary spatially by radius away from the center of the hurricane and quadrant of the hurricane (Young 2003; Moon et al. 2003; Fan et al. 2009; Collins et al. 2018). Spatial variability in wave fields is introduced by asymmetry in hurricane wind speeds due to hurricane translation speed, misalignment between the winds and waves due to wind field curvature (Moon et al. 2003), and bimodality due to the combination of preexisting swell and locally generated seas. Wave fields can also exhibit spatial variability without wind asymmetry by dynamic, or extended, fetch (e.g., Bowyer and MacAfee 2005; Kudryavstev et al. 2015). Waves generated on the right side of hurricanes may travel at a group velocity near the translational speed of the hurricane, effectively becoming locked to the overlying wind field. The influence of currents on dynamic fetch during hurricanes has not been investigated, to our knowledge.

Finally, recent work investigating wave-current interaction over meso- to large-scale features has described experimental limitations due to model spatial resolution (Rapizo et al. 2018), as the gradients in the currents are important for the evolution of the wavenumber, shoaling, and refraction. Sensitivity of bulk wave fields under tropical cyclones to model spatial resolution was recently quantified by Chen et al. (2018). The authors found that maximum wave heights, and spatial gradients in wave height and wavelength under tropical cyclones were poorly estimated with wave model spatial resolutions that are often employed $[O(10) \mathrm{km}]$. The degree of sensitivity is dependent on the tropical cyclone's propagation speed, radius of maximum winds, and propagation direction relative to the grid discretization (Chen et al. 2018). We address these limitations with a 5-km model grid, which represents a doubling of the resolution used in most previous studies.

In this work, we investigate the effects of wavecurrent interaction over the Gulf Stream on Hurricane Matthew (2016) wave fields by analyzing bulk wave parameters and frequency-directional wave spectra. We find that inclusion of the Gulf Stream in hurricane simulations is necessary to simulate offshore and coastal waves and water levels. This paper is organized as follows: section 2 discusses Hurricane Matthew in the South Atlantic Bight (SAB). Section 3 reviews the methodology, including the hydrodynamic and wave modeling components, and the coupling experiments simulated. Section 4 analyzes the effect of wave-current interaction between wave fields and storm-driven circulation and the Gulf Stream on bulk wave parameters and wave spectra organized by hurricane quadrant. 

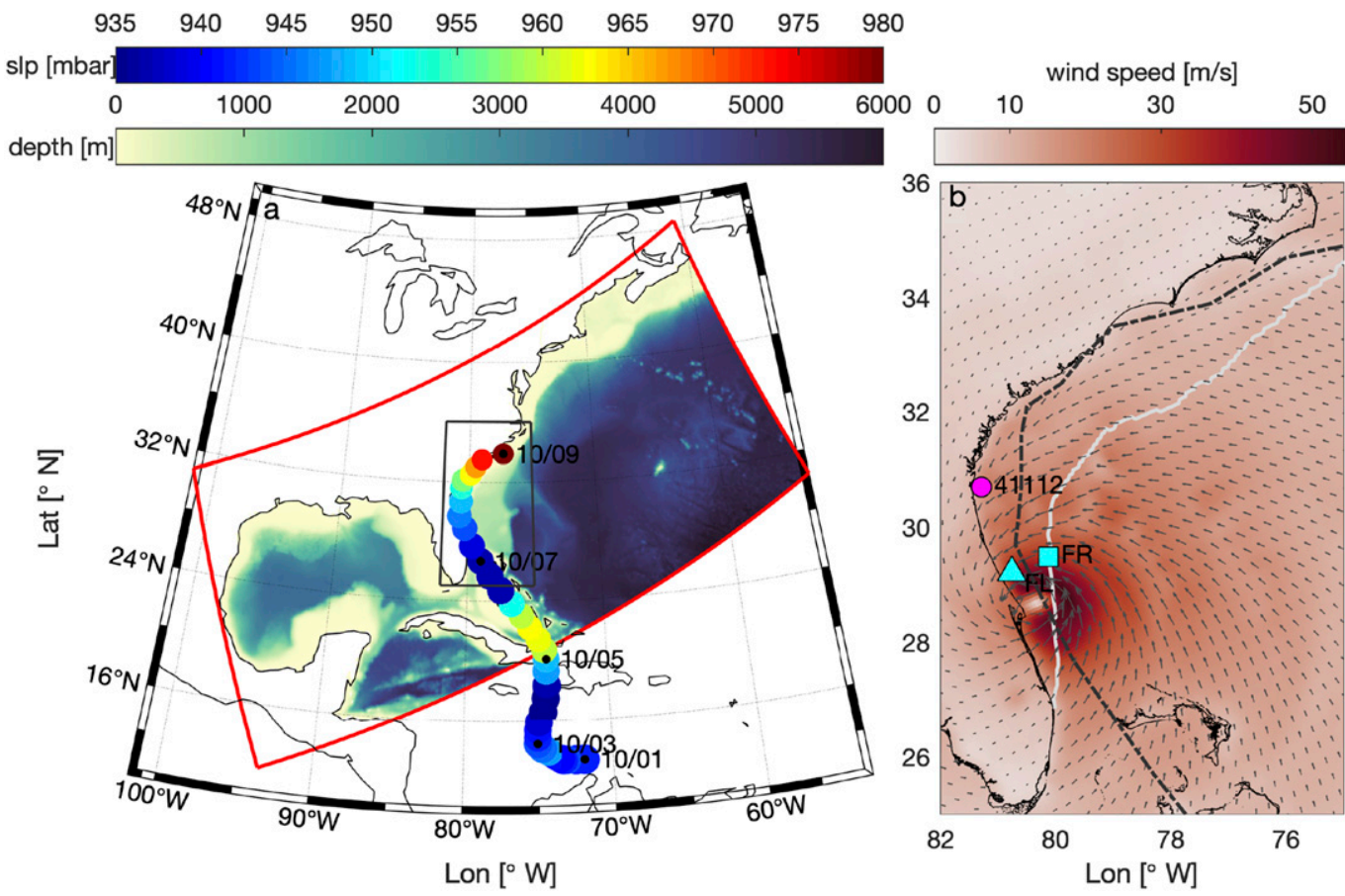

FIG. 1. (a) Ocean depth within the coupled model domain (shaded), which extends over the U.S. East and Gulf Coasts at 5-km horizontal resolution (red box). The best track position, maximum wind speed (related to size of points), and minimum pressure (color of points) show the evolution of Hurricane Matthew from 1 to 9 Oct 2016. The black box represents the domain in (b). (b) Wind speed (color) and direction (vectors) at $10 \mathrm{~m}$ above sea level at 1200 UTC 7 Oct 2016 as COAMPS-TC atmospheric forcing to the coupled model. The light gray line is the position of the core of the Gulf Stream on 1 Oct 2016. The dashed dark gray line is the best track position of Hurricane Matthew. The cyan triangle (FL quadrant of the hurricane) and square (FR) are two points at which frequency-directional wave spectra are analyzed. The magenta circle is a point at which bulk wave parameters in the fully coupled simulation are compared with measurements by NDBC wave buoy 41112 .

We contextualize the importance of wave-current interaction over the Gulf Stream for the coast in section 5. Brief concluding remarks are found in section 6.

\section{Hurricane Matthew and the SAB}

Hurricane Matthew was a Saffir-Simpson category 5 hurricane that impacted the U.S. East Coast in October 2016 (Fig. 1a). The hurricane developed in the Caribbean Sea, where it rapidly intensified and caused significant destruction. Hurricane Matthew then transited across the Gulf Stream near the Florida Strait and paralleled the SAB coastline within $50 \mathrm{~km}$ of the coast for nearly two days as a category 3 hurricane, during which the right side of the hurricane was directly over the Gulf Stream (Fig. 1b). The hurricane made landfall in South Carolina at 1500 UTC 8 October 2016 and ultimately moved offshore as an extratropical storm. During the close passage to Florida, Hurricane Matthew decreased in strength and intensity. Maximum wind speeds decreased from 60 to $40 \mathrm{~m} \mathrm{~s}^{-1}$, minimum sea level pressure (SLP) increased from 937 to
$967 \mathrm{mb}(1 \mathrm{mb}=1 \mathrm{hPa})$, and the radius of $\sim 33 \mathrm{~m} \mathrm{~s}^{-1}$ wind speeds was between 35 and $75 \mathrm{~km}$ during this transit (HURDAT2; Landsea and Franklin 2013; Fig. 1a). The propagation speed of the storm was on the order of $5-10 \mathrm{~m} \mathrm{~s}^{-1}$ through the SAB (HURDAT2; Landsea and Franklin 2013).

Coastal impacts during Hurricane Matthew were severe, particularly in Haiti, which experienced significant loss of life and a humanitarian and economic crisis. In the SAB, the United States accrued several billion dollars of damage because of flooding due to storm surge and rainfall, and coastal erosion due to extreme waves and water levels (National Hurricane Center; nhc.noaa.gov). Maximum storm surge was reported to be $\sim 3 \mathrm{~m}$ in parts of Florida. The ability to predict coastal impacts during extreme events such as hurricanes is limited in part by prediction of the wave field, since 1) wave breaking at the coast induces elevated water levels and sediment transport, and 2) waves contribute momentum via radiation stresses or vortex forces, and the spatially integrated effect of Stokes flows can result in elevated water levels. Wave-current interaction of waves with 
both large-scale currents and storm-driven circulation can modify the distribution and magnitude of wave energy and water levels at the coast.

The track of Hurricane Matthew was unique compared to many hurricanes that impact the SAB. The hurricane paralleled the SAB coast within close proximity instead of approaching it perpendicularly. As a result, Hurricane Matthew interacted with the Gulf Stream for a long duration. Interaction between hurricanes and the Gulf Stream is multivariate. Hurricanes intensify over the warm waters of the Gulf Stream. Variability in Gulf Stream transport associated with hurricane passage has been observed (Todd et al. 2018), and short-term weakening of transport has been correlated to elevated coastal water levels in the SAB (Ezer et al. 2017). For this work, the track of Hurricane Matthew allows us to explore wave-current interaction of mixed sea states beneath different quadrants of the hurricane with the Gulf Stream.

\section{Model setup and experiment}

The Coupled Ocean-Atmosphere-Wave-Sediment Transport modeling system (COAWST; Warner et al. $2008,2010,2019$ ) was used to explore wave-current interaction over the Gulf Stream during Hurricane Matthew. In this application, the Regional Ocean Modeling System (ROMS; version 885) and Simulating Waves Nearshore model (SWAN; version 41.20, as integrated into COAWST) components were two-way coupled using the Model Coupling Toolkit and forced by an atmospheric reanalysis product. The COAWST framework is skillful at simulating hurricane tracks and intensity, hurricane wave fields, sea surface properties, and sediment dynamics during hurricane passage (e.g., Warner et al. 2010, 2017; Olabarrieta et al. 2012; Zambon et al. 2014a,b; Zang et al. 2018), and has been used to study wave-current interaction across a range of spatial scales (e.g., Kumar et al. 2012; Olabarrieta et al. 2014; Wandres et al. 2017).

\section{a. Ocean model}

ROMS is a three-dimensional, free surface, terrainfollowing hydrodynamic model that solves the Reynoldsaveraged Navier Stokes equations assuming hydrostatic equilibrium and Boussinesq approximations, using a finite differences method on an Arakawa $\mathrm{C}$ grid (Haidvogel et al. 2000, 2008; Shchepetkin and McWilliams 2005; Warner et al. 2008). Simulations were performed for 1-9 October 2016 over a curvilinear grid encompassing the entire U.S. East and Gulf Coasts at $\sim 5$-km horizontal resolution with 16 terrain-following sigma layers (Fig. 1). The vertical stretching parameters were $\theta_{s}=10, \theta_{b}=0.4$, and $T_{\text {cline }}=50 \mathrm{~m}$. Vertical resolution in the surface ocean varied vertically from $<1$ to $5 \mathrm{~m}$ in the vicinity of the Gulf Stream. The model grid has been implemented for the investigation of other North Atlantic hurricane dynamics (Warner et al. 2010; Olabarrieta et al. 2012; Warner et al. 2017) and is detailed in Warner et al. (2010). The ROMS model is run with a third-order upstream horizontal advection scheme and fourth-order centered vertical advection scheme for tracers and momentum, with a 180 -s time step for the baroclinic mode and a 6-s time step for the barotropic mode. Horizontal viscosity and diffusion are 0.2 and $0.1 \mathrm{~m}^{2} \mathrm{~s}^{-1}$, respectively. Vertical mixing follows the $k-\varepsilon$ turbulence closure with a Kantha and Clayson (1994) stability function, implemented via the generic length-scale approach (Warner et al. 2005). Turbulence is injected into the surface ocean by wave breaking. Background vertical viscosity and diffusion are $10^{-6}$ and $10^{-5} \mathrm{~m}^{2} \mathrm{~s}^{-1}$, respectively. Bottom stress follows a logarithmic drag law with a roughness length of $0.005 \mathrm{~m}$. The western and northern boundaries of the model are closed. On the eastern and southern boundaries, free surface and barotropic velocity variations are specified with Chapman and Flather boundary conditions, respectively. Baroclinic velocity and tracer variations are specified with radiation boundary conditions. A zero gradient condition is imposed on turbulent kinetic energy at the open boundaries. The domain was initialized with temperature, salinity, barotropic and baroclinic velocities, and free-surface elevations simulated by a semioperational COAWST forecast system (http:// geoport.whoi.edu/thredds/COAWST_catalog.html) for 1 October 2016. The domain of the semi-operational forecast system is the same as the one used here and, although the atmospheric forcing of the forecast system differs from that imposed here, the required spinup of the model is negligible. The model is forced by TPXO tides (Egbert and Erofeeva 2002) at the open boundaries and atmospheric forcing at the surface. The atmospheric forcing is described in section $3 \mathrm{c}$. The hurricane enters the domain on 5 October 2016.

\section{b. Wave model}

SWAN is a third-generation spectral wave model that solves for the evolution of wave action, accounting for wave propagation, shoaling, and refraction over bathymetry and currents, wind wave growth, dissipation due to whitecapping, bottom friction, and depth-limited breaking, and nonlinear triad and quadruplet wavewave interactions (Booij et al. 1999). SWAN simulations were performed over the same grid as defined for ROMS. Spectra were discretized with $5^{\circ}$ directional resolution and 48 frequency bins distributed logarithmically 
from 0.04 to $1 \mathrm{~Hz}$. Above $1 \mathrm{~Hz}$, a spectral tail was applied such that energy density $E \propto f^{4}$.

The wave action balance equation describes wave growth, dissipation, and evolution in the presence of spatially varying bathymetry and ambient currents. Wave action $N$ is

$$
N=\frac{E(\sigma, \theta)}{\sigma},
$$

which is a conserved quantity in the presence of mean currents. The term $E$ is the energy density as a function of relative radian frequency $\sigma$ and direction $\theta$. The relative radian frequency $\sigma$ is related to the absolute radian frequency $\omega$ such that

$$
\omega=\sigma+\mathbf{k} \cdot \mathbf{u},
$$

where $\mathbf{k}$ is the wavenumber vector and $\mathbf{u}$ is the mean current. This relationship encompasses Doppler shift of the absolute frequency by the mean flow. The wave action balance equation is

$$
\frac{\partial N}{\partial t}+\nabla_{\mathbf{x}} \cdot\left[\left(\mathbf{c}_{\mathbf{g}}+\mathbf{u}\right) N\right]+\frac{\partial c_{\sigma} N}{\partial \sigma}+\frac{\partial c_{\theta} N}{\partial \theta}=\frac{S_{\text {tot }}}{\sigma},
$$

where $\left(\mathbf{c}_{\mathbf{g}}+\mathbf{u}\right)$ is the propagation velocity in $x$ and $y$ modified by the mean current, $c_{\sigma}$ and $c_{\theta}$ are the propagation velocities in $\sigma$ and $\theta$, and $S_{\text {tot }}$ represents the nonconservative source, sink, and redistribution terms of energy density. The third and fourth terms in the wave action balance equation are shifting of $\sigma$ and refraction of $\theta$, respectively, by bathymetry and currents. The source and sink terms are

$$
S_{\mathrm{tot}}=S_{\mathrm{in}}+S_{\mathrm{nl}}+S_{\mathrm{dw}}+S_{\mathrm{bf}},
$$

where $S_{\text {in }}$ is wave growth due to wind input, $S_{\mathrm{nl}}$ is spectral redistribution of energy by nonlinear quadruplet wave-wave interactions, $S_{\mathrm{dw}}$ is dissipation due to whitecapping, and $S_{\mathrm{bf}}$ is dissipation due to bottom friction, which is nonzero from the shelf break toward the coast. The term $S_{\text {in }}$ is energy input to the wave spectrum, $S_{\mathrm{dw}}$ and $S_{\mathrm{bf}}$ are energy loss from the wave spectrum, and $S_{\mathrm{nl}}$ represents the transfer of energy from the peak frequency of the wave spectrum to lower and higher frequencies. The term $S_{\text {in }}$ encompasses the effect of mean currents on the relative wind speed.

SWAN was implemented with third-generation Komen et al. (1984) formulations for $S_{\mathrm{in}}$ and $S_{\mathrm{dw}}$, such that

$$
S_{\mathrm{dw}}(\sigma, \theta)=-\Gamma \tilde{\sigma} \frac{k}{\tilde{k}} E(\sigma, \theta),
$$

where $\Gamma$ is a coefficient dependent on steepness and $k$ is wavenumber. The overbar denotes a spectral mean. Default values were used for the coefficients describing the rate of whitecapping dissipation and the dependence on steepness (Komen et al. 1984; SWAN Team 2019). Bottom friction was implemented using the Hasselmann et al. (1973) formulation with a constant friction coefficient of $0.038 \mathrm{~m}^{2} \mathrm{~s}^{-3}$. Spectral redistribution of energy by nonlinear quadruplet wave-wave interactions was calculated using the discrete interaction approximation. Nonlinear triad wave-wave interactions were not included because they only become important in shallow water. Diffraction was not included in the simulations. Nonlinear wave-wave interaction and dissipation terms do not directly include the mean current. As a result, spectral wave models poorly simulate redistribution of wave energy and the development of a spectral tail and underestimate the dissipation rate associated with wave breaking in opposing wave-current regimes (Rapizo et al. 2017). The wave action balance equation was solved using the implicit, first order, backward space, backward time scheme with a 300 -s time step. SWAN was initialized with a stationary computation for the prescribed wind field on 1 October 2016.

\section{c. Atmospheric forcing}

The COAWST model was forced by a Coupled Ocean-Atmosphere Mesoscale Prediction System for Tropical Cyclones (COAMPS-TC) product specifically reanalyzed to reduce errors in the track, minimum SLP, and radius of maximum winds of the hurricane for coastal change studies (Doyle et al. 2014; Fig. 1b). COAMPS-TC provided longwave and shortwave radiation, SLP, wind velocity at $10 \mathrm{~m}$ above the ocean surface, precipitation rate, air temperature, and relative humidity at 4-km spatial resolution and 3-h temporal resolution. These variables were interpolated onto the COAWST grid.

\section{d. Coupling dynamics}

ROMS and SWAN were coupled within the COAWST framework at a coupling time step of $900 \mathrm{~s}$. Wavecurrent interaction included both the effect of the mean current on the waves and the effect of the waves on the current. To account for the effect of the mean current on the waves, current velocities and water level were exchanged from ROMS to SWAN at each coupling time step. The absolute wave group velocity $c_{g a}$ was modified by a depth-weighted current $\tilde{u}$, defined following a simplification of the Kirby and Chen (1989) formulation for vertically sheared surface currents 
applied for the wavenumber at the peak frequency $k_{p}$ as

$$
\tilde{u}=\frac{2 k_{p}}{\sinh 2 k_{p} d} \int_{-h}^{0} u(z) \cosh 2 k_{p}(d+z) d z,
$$

where $d$ is depth and $u(z)$ is a vertically varying current. This implementation does not include a second-order $k(d \tilde{u} / d k)$ term. This representation of a single $\tilde{u}$ for all wavenumbers can introduce errors (Banihashemi et al. 2017), particularly for wave spectra with wide frequency distributions over strongly sheared currents. Improving this is an active area of research (Banihashemi and Kirby 2019). The exchange of water level allows for changes in depth-limited breaking at the coast due to tidal fluctuations or storm surge. The contribution of the waves to the circulation is included in COAWST through the vortex force formalism (Uchiyama et al. 2010; Kumar et al. 2012). During each coupling time step, total wave dissipation, significant wave height $H_{s}$, mean and peak wavelength $L$ and $L_{p}$, respectively, mean wave direction $D_{m}$, and peak wave period $T_{p}$ are passed from SWAN to ROMS.

Air-sea fluxes of heat, freshwater, and momentum were calculated by ROMS using COARE 3.0 parameterizations (Fairall et al. 1996, 2003). Inclusion of waves provides ocean surface roughness elements and thus modulates air-sea fluxes. However, understanding of the momentum flux at high wind speeds, and in complex wind and wave regimes is limited, due in part to a paucity of observations of the atmospheric boundary layer and surface wave characteristics at high wind speeds and wave heights, and limited understanding of the wave components that support the momentum flux. Under hurricane conditions, multiple boundary layer regimes can coexist across time and space. For example, wave steepness or wave age do not capture multimodal wave conditions under hurricanes, but might be sufficient in regions outside of a hurricane's radius of maximum wind speeds. Holthuijsen et al. (2012) described the wave crest length as a key variable in describing surface wave roughness to account for bimodality. We note that the results are indeed sensitive to the formulation of the surface wave roughness, though experimentation with different formulations is not within the scope of this work. The reader is referred to Olabarrieta et al. (2012) for an analysis of the effect of four formulations (Charnock 1955; Taylor and Yelland 2001; Oost et al. 2002; Drennan et al. 2003) on hurricane wave and water level predictions.

The modulation of wind stress was based on a surface wave roughness length $Z_{o, w}$ formulation
(Taylor and Yelland 2001), which depends on wave steepness as

$$
Z_{o, w}=1200 H_{s}\left(\frac{H_{s}}{L_{p}}\right)^{4.5} .
$$

The COARE algorithm was modified to include an upper limit of $2.85 \times 10^{-3} \mathrm{~m}$ on the surface wave roughness length (Davis et al. 2008), which has been observed in high wind conditions (e.g., Powell et al. 2003; Donelan et al. 2004). The Taylor and Yelland (2001) formulation yields improved calculation (Drennan et al. 2005) of the momentum flux compared to some wave age formulations (e.g., Drennan et al. 2003; Oost et al. 2002) or bulk formulations [e.g., Charnock (1955) with varying Charnock parameter] for mixed sea states.

\section{e. Experiments}

Three model experiments were performed to isolate wave-current interaction over Gulf Stream currents versus storm-driven circulation. In the first simulation [fully coupled (FC)], the model setup was as described above, with two-way coupling between the ocean and wave models. In the second simulation [no Gulf Stream (no GS)], the ROMS model was initialized without baroclinicity: the free surface, baroclinic, and barotropic current velocities were initialized at zero, and temperature and salinity were held uniform at $10^{\circ}$ and $30^{\circ} \mathrm{C}$, respectively. Tides were imposed, and storm-driven circulation was allowed to develop as in the FC simulation. Response to tidal forcing developed over five days before the hurricane entered the model domain. ROMS and SWAN were coupled as in the FC simulation. The final simulation [no wave-current interaction (no WCI)] included Gulf Stream currents and allowed storm-driven circulation to develop, but ROMS passed a current of zero to SWAN, removing the effect of the mean flow on the wave field. Note that surface roughness was still modified by the wave field and the effect of the waves on the current was included.

Wind stress, currents, Stokes drift currents, significant wave height $\left(H_{s}\right)$, absolute mean and peak wave period ( $T_{m}$ and $T_{p}$, respectively), mean and peak wavelength ( $L$ and $L_{p}$, respectively), and mean wave direction $\left(D_{m}\right)$ were output at hourly intervals over the computational grid. Additionally, these parameters were interpolated to a location collocated with National Data Buoy Center (NDBC; ndbc.noaa.gov) wave buoy 41112 (Fig. 1b). Spectrally integrated wave growth due to wind input $\left(S_{\text {in }}\right)$, dissipation due to whitecapping $\left(S_{\mathrm{dw}}\right)$, and redistribution of energy by nonlinear quadruplet wave-wave interactions $\left(S_{\mathrm{nl}}\right)$ were also output at hourly intervals over the computational grid. Frequency-directional spectra 

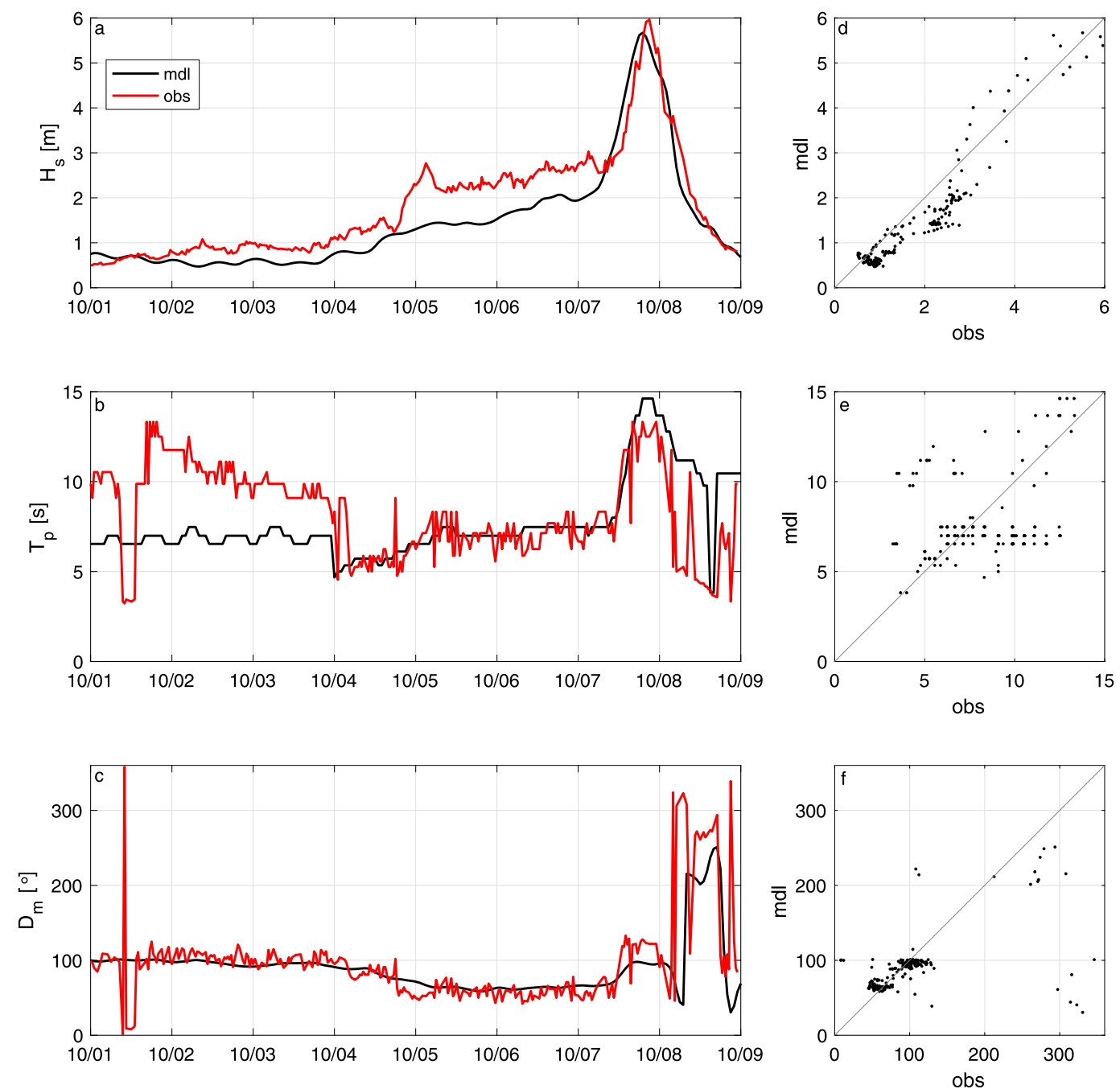

FIG. 2. Comparison of bulk wave parameters (a),(d) significant wave height $H_{s}$, (b),(e) peak wave period $T_{p}$, and (c),(f) mean wave direction $D_{m}$ between the fully coupled simulation (mdl) and observations (obs) by NDBC wave buoy 41112 .

were output at two points at the midpoints of the frontleft $\left(\mathrm{FL} ; 29.498^{\circ} \mathrm{N}, 80.128^{\circ} \mathrm{W}\right)$ and front-right $(\mathrm{FR}$; $29.214^{\circ} \mathrm{N}, 80.763^{\circ} \mathrm{W}$ ) quadrants of Hurricane Matthew as it paralleled the Florida coastline, with the right side of the hurricane interacting with the Gulf Stream (Fig. 1b). At these two locations, frequency-directional distributions of $S_{\mathrm{in}}, S_{\mathrm{dw}}, S_{\mathrm{nl}}$, and, only at FL, dissipation due to bottom friction $\left(S_{\mathrm{bf}}\right)$, were output as well.

\section{f. Validation}

Validation of the fully coupled model is partially presented here with comparison of modeled wave parameters to wave buoy observations, with further analysis as part of a larger effort. The goal of this work is to assess the potential contribution of wave-current interaction over the Gulf Stream to the waves and water levels; hence, we focus on the relative differences between the simulations.

Hurricane Matthew produced large waves $(\sim 15 \mathrm{~m})$ and water level anomalies $(\sim 3 \mathrm{~m})$ within the SAB. Comparisons of modeled $H_{s}, T_{p}$, and $D_{m}$ to observations by NDBC wave buoy 41112 are reasonable (Fig. 2). Wave buoy 41112 is located in $15 \mathrm{~m}$ of water; comparisons are influenced by bottom friction, interaction between tides and surge, depth-limited breaking, and model representation of the shelf bathymetry. Comparisons are sensitive to the forcing fields and related to errors in the asymmetry and strength of the wind fields. Before the hurricane entered the model domain on 5 October 2016, $T_{p}$ was largely underestimated because waves from the secondary Tropical Storm Nicole were not imposed on the boundaries of the domain. 

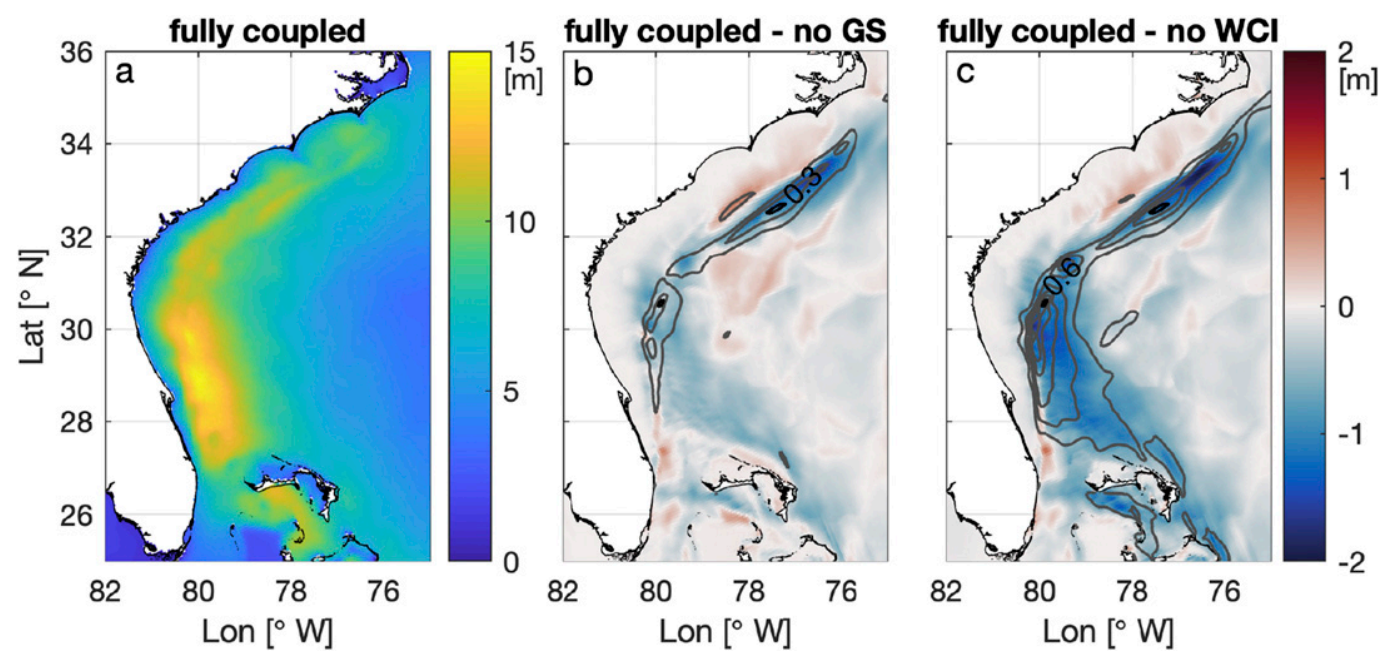

FIG. 3. (a) Spatially varying maximum significant wave height $H_{s}$ in the fully coupled (FC) simulation over the full time period (1-9 Oct 2016). (b) Differences (color) in spatially varying maximum $H_{s}$ between the FC and no Gulf Stream (no GS) simulations over the full time period, where positive indicates larger values in the FC simulation. In contours of $0.1 \mathrm{~m}^{2}$, variance of the differences in $H_{s}$ between the FC and no GS simulations over the full time period. Black contours are of 0.3 and $0.6 \mathrm{~m}^{2}$. (c) Differences (color) in spatially varying maximum $H_{s}$ between the FC simulation and the simulation without wave-current interaction (no WCI) over the full time period, where positive indicates larger values in the FC simulation. In contours of $0.1 \mathrm{~m}^{2}$, variance of the differences in $H_{s}$ between the FC and no WCI simulations over the full time period. Black contours are as in (a).

The $H_{s}$ values were underestimated by $\sim 0.5 \mathrm{~m}$ until the peak of the storm, when $H_{s}$ values were underestimated by $10 \mathrm{~cm}$. We suspect that this was a result of low model resolution near the Caribbean Islands, which blocked wave energy from propagating into the $\mathrm{SAB}$ when Hurricane Matthew was to the south. Comparisons between modeled wave parameters to other nearby buoys yielded similar results.

\section{Results}

Results from the FC simulation reveal the evolution of Hurricane Matthew in the SAB between 6 and 9 October 2016. In the SAB, the Gulf Stream is locked to the continental shelf break. Before Hurricane Matthew entered the model domain, maximum surface currents in the core of the Gulf Stream were $1.5-2 \mathrm{~m} \mathrm{~s}^{-1}$ and the resolved horizontal gradient in Gulf Stream surface currents along its western edge was $0.7 \mathrm{~m} \mathrm{~s}^{-1}$ per $5 \mathrm{~km}$. Maximum tidal currents on the continental shelf were $\leq 0.5 \mathrm{~m} \mathrm{~s}^{-1}$. Over the period Hurricane Matthew was in the SAB, maximum surface currents in the Gulf Stream core were nearly $3 \mathrm{~m} \mathrm{~s}^{-1}$, suggesting local enhancement of the Gulf Stream by storm-driven (wind-, SLP-, wave-driven) circulation. Currents reached $\sim 0.5-1.75 \mathrm{~m} \mathrm{~s}^{-1}$ on the continental shelf and were dominated by storm-driven circulation over tidal circulation. There was significant spatial variability in maximum surface currents, both in the Gulf Stream and over the shelf, caused by variation in the intensity of the hurricane, spatial variation in the strength of the hurricane winds, and underlying tidal or Gulf Stream currents.

As the hurricane transited through the $\mathrm{SAB}$, the highest waves were generated beneath the right side of the hurricane (Fig. 3a), where winds were stronger than the left side due to the effect of the hurricane propagation on the wind speed. Spatial variations in maximum $H_{s}$ were also driven by variations in the intensity of the hurricane (Fig. 1a). Large maximum $H_{s}$ in the southern SAB were related to strengthening of Hurricane Matthew as it emerged from the Caribbean Sea, and, conversely, small maximum $H_{s}$ in the northern $\mathrm{SAB}$ were the result of weakening of the hurricane. Differences between maximum $H_{s}$ in the FC and no GS simulations elucidate the effect of Gulf Stream currents on the hurricane wave field through wave-current interaction (Fig. 3b). Maximum $H_{s}$ in the FC simulation was $0.5-1 \mathrm{~m}$ smaller than in the no GS simulation. The differences were small on the shelf, reinforcing that storm-driven currents dominated the shelf circulation and indicating that wave-current interaction over the Gulf Stream did not significantly modify the maximum wave heights. However, the differences were greatest offshore of the shelf break, indicating that the Gulf Stream modulated the maximum wave heights. Spatially coherent differences in maximum $H_{s}$ were constrained to the Gulf 
Stream (Fig. 3b). Variance (var) of the differences in $H_{s}$ between the FC and no GS simulations $\left(\Delta H_{s}\right)$ was calculated as

$$
\operatorname{var}=\frac{1}{T_{t=1}^{T}}\left[\Delta H_{s}(t)-\overline{\Delta H_{s}}\right]^{2},
$$

where $t$ is time and the overbar denotes the time mean. The largest variance in $\Delta H_{s}$ also occurred over the Gulf Stream (contour lines in Fig. 3b), indicating that wavecurrent interaction over the Gulf Stream yielded largely varying differences in $H_{s}$ over the simulation period. This signal is expected, as the hurricane was moving, the wave and current fields were rapidly evolving, and the effect of the interaction varied in space and time. Maximum $H_{s}$ in the no WCI simulation were nearly $2 \mathrm{~m}$ larger than in the FC simulation (Fig. 3c). The spatial signature of the differences in maximum $H_{s}$ and variance of $\Delta H_{s}$ between the FC and no WCI simulations was similar to that between the FC and no GS simulations. Variance of $\Delta H_{s}$ between the FC and no WCI simulations was roughly double the magnitude of that between the FC and no GS simulations (Fig. 3c). The ratio of variances indicates the relative importance of wave-current interaction over Gulf Stream currents or over all currents, including storm-driven circulation (Figs. 3b,c). From the southern to middle SAB, the ratio of variances is $0.5-0.6$, meaning that most differences in $H_{s}$ were controlled by wave-current interaction over the Gulf Stream. However, the hurricane was also strongest in this part of the SAB, so wave-current interaction with the storm-driven circulation was equally important. Local enhancement of the Gulf Stream was strongest here as well. Toward the northern SAB, the ratio of variances approached 1 , indicating that wavecurrent interaction over the Gulf Stream accounted for all of the differences in $H_{s}$ between the $\mathrm{FC}$ and no WCI simulations. Hurricane Matthew was weakening in the northern SAB. For the remainder of the text, we focus on comparison of the FC and no GS simulations.

Wave-current interaction between hurricane wave fields and storm-driven circulation is spatially variable because of the rotation, asymmetry, and propagation of hurricane winds and the complexity of the sea states generated (Collins et al. 2018). The right side of Hurricane Matthew interacted with the Gulf Stream as it paralleled the Florida coast, which induced further spatial variability. To assess the spatial variability of these fields, we use a frame of reference centered on the hurricane and its time-varying propagation direction. The center of the hurricane at each hour was identified from a combination of HURDAT2 data (Landsea and Franklin 2013) and minimum SLP from the COAMPS-TC atmospheric forcing, which was used to estimate the best track position at times in between the output resolution of HURDAT2. Wave, wind, and current variables within a $100-\mathrm{km}$ radius from the center were rotated into the frame of reference of the propagating hurricane (as in Fig. 4). Land values were masked. At 0600 UTC 7 October 2016, Hurricane Matthew crossed the Gulf Stream just north of the Florida Strait and propagated along the coast until 8 October 2016. We chose a representative snapshot at 1300 UTC 7 October 2016 to illustrate the effect of wave-current interaction over the Gulf Stream (Fig. 1). First, we analyze bulk wave parameters and spectrally integrated source and sink terms in the wave action balance equation in the frame of reference defined above. Then we assess frequencydirectional wave spectra and source and sink terms at two locations in the SAB that represent the FL and FR quadrants of the hurricane (Fig. 1).

\section{a. Bulk effect of wave-current interaction}

Significant wave height was largest in the FR quadrant of the hurricane, coincident with the highest wind speeds (Fig. 4a). Maximum $H_{s}$ was $14.6 \mathrm{~m}$ in a $100-\mathrm{km}$ radius from the hurricane center at 1300 UTC 7 October 2016. The $H_{s}$ was smaller in the rear half of the hurricane and toward the coast. Peak wave period was longest in the front half of the hurricane, preferentially in the FL quadrant (Fig. $4 \mathrm{~b}$ ). The $T_{p}$ was $>10 \mathrm{~s}$ in the $100-\mathrm{km}$ radius from the hurricane center. Mean wave directions rotated with the wind fields, coming from $\sim 180^{\circ}$ in the rear-right (RR) quadrant and $\sim 100^{\circ}$ in the FR quadrant. The $D_{m}$ was decoupled from the winds on the left side of the hurricane, approaching from $\sim 90^{\circ}$ in the FL quadrant, likely as a result of refraction over the continental shelf and bimodal sea states such that mean wave direction and peak wave direction were distinct (Fig. 4c). Bimodal seas represented the combination of swell waves propagating from prior hurricane positions and seas generated beneath the hurricane. Mean wavelength was largest in the FR quadrant of the hurricane (Fig. 4d). The $L$ did not appear to be directly related to the highest wind speeds, but had a similar spatial structure to $H_{s}$. Mean wave steepness $s$ was calculated as

$$
s=\tilde{k} \sqrt{E} \approx \frac{H_{s}}{L}
$$

where $\tilde{k}$ is the mean wavenumber. Mean wave steepness was large everywhere under the hurricane and decreased toward the coast (Fig. 4e). Comparison of these variables by hurricane quadrant to the no GS simulation indicates the spatial variability of the effect of wavecurrent interaction with the Gulf Stream on bulk wave 

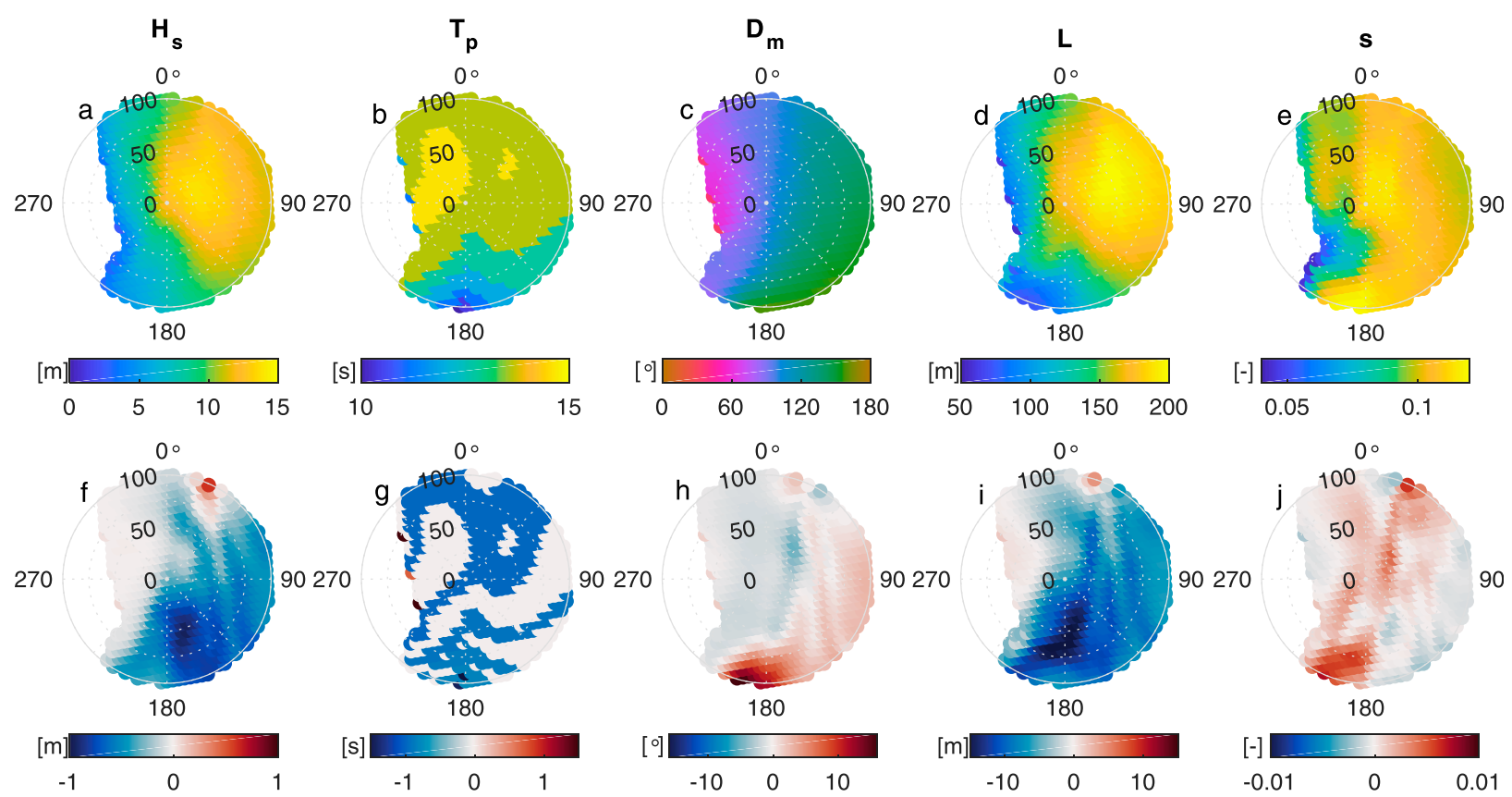

FIG. 4. (a) Significant wave height $H_{s}$, (b) peak wave period $T_{p}$, (c) mean wave direction $D_{m}$, (d) mean wavelength $L$, and (e) mean wave steepness $s$ in the fully coupled (FC) simulation at 1300 UTC 7 Oct 2016. The polar plots are transformed into hurricane coordinates. The radial axis is the distance $(\mathrm{km})$ from the center of the hurricane, and the directional axis is from the direction of translation of the hurricane (rotated to $0^{\circ}$ ). The right side of the hurricane interacts with the Gulf Stream. (f)-(j) Differences in variables between the FC and no Gulf Stream simulations, where positive indicates larger values in the FC simulation.

parameters. There were smaller $H_{s}$ and shorter $L$ on the right side of the hurricane in the FC simulation compared to the no GS simulation (Figs. 4f,i). The largest differences were in the RR quadrant, just behind the eye of the hurricane, where $H_{s}$ was $1 \mathrm{~m}$ smaller and $L$ was $15 \mathrm{~m}$ shorter in the FC simulation. The values of $T_{p}$ were $\sim 1 \mathrm{~s}$ shorter in the FR quadrant in the FC simulation (Fig. 4g). Notably, waves were $\sim 10 \%$ steeper under the hurricane in the FC simulation, indicating that differences in $H_{S}$ and $L$ between the simulations were not proportional (Fig. 4j). Overall, wave-current interaction over the Gulf Stream yielded smaller $H_{s}$, smaller $T_{p}$, shorter $L$, changes to $D_{m}$ on the order of $10^{\circ}$, and steeper waves.

The spatial structures of wave energy source and sink terms under the hurricane at 1300 UTC 7 October 2016 in the FC simulation were coherent (Fig. 5). Wave growth due to wind input, dissipation due to whitecapping, and spectral redistribution of energy by quadruplet wavewave interactions were largely constrained to within a $50-\mathrm{km}$ radius in the FR quadrant of Hurricane Matthew (Figs. 5a-c). Large waves outside this region of wave growth were somewhat decoupled from the wind and were likely swell generated elsewhere (Fig. 4a). This was supported by the long $T_{p}$ outside of the area of wave growth due to wind input (Fig. $4 \mathrm{~b}$ ). The $S_{\mathrm{in}}, S_{\mathrm{dw}}$, and $S_{\mathrm{nl}}$ depend on wave steepness and the shape of the wave spectrum. As a result, differences in these terms between the FC and no GS simulations were highly correlated with differences in mean wave steepness between the simulations (Figs. $4 \mathrm{j}$ and $5 \mathrm{f}-\mathrm{h}$ ). Compared to the no GS simulation, $S_{\mathrm{in}}, S_{\mathrm{dw}}$, and $S_{\mathrm{nl}}$ were $\sim 5 \%, \sim 15 \%$, and $\sim 30 \%$ larger, respectively, in the FC simulation within a $50-\mathrm{km}$ radius in the FR quadrant of the hurricane. These terms were also slightly larger over the continental shelf, on the left side of the hurricane. Surface wave roughness as formulated by Taylor and Yelland (2001) depends on wave steepness, and thus exhibited a similar spatial structure in the FC simulation to the other terms (Fig. 5d). Differences in surface wave roughness between the FC and no GS simulations were again correlated with differences in mean wave steepness between the simulations (Fig. 5i). Increased surface wave roughness in the FC simulation implies a larger wind stress imposed on the ocean surface. Last, the magnitude of the Stokes drift in the FC simulation was largest on the left side of the hurricane (Fig. 5e). The magnitude of the Stokes drift in the FC simulation was either the same or smaller under the hurricane than in the no GS simulation (Fig. 5j).

Angles between the wind stress direction, surface current direction, and mean wave direction varied by hurricane quadrant in the $100-\mathrm{km}$ radius from the hurricane center at 1300 UTC 7 October 2016 (Fig. 6). 

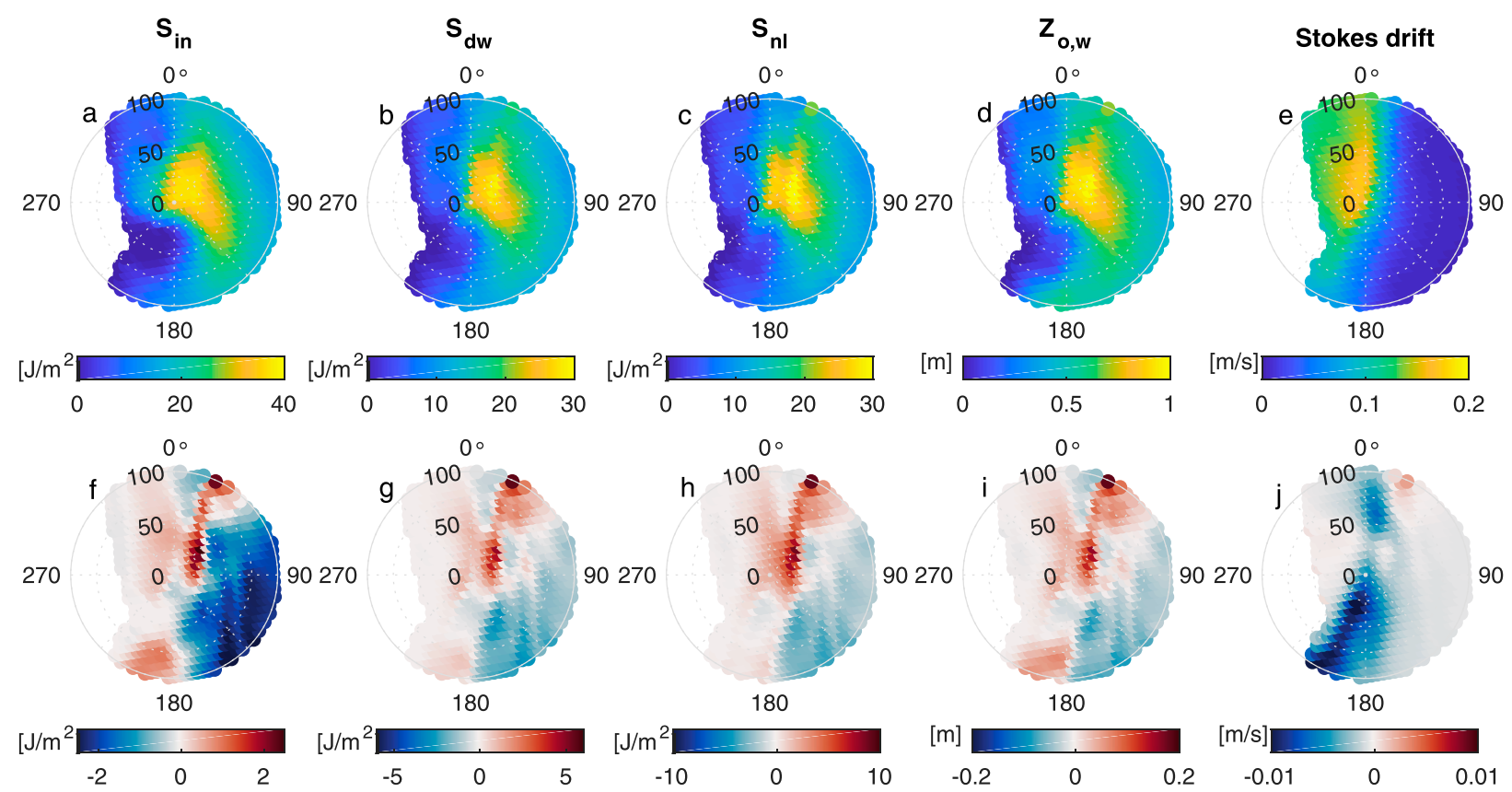

FIG. 5. (a) Wave growth due to wind input $S_{\text {in }}$, (b) dissipation due to whitecapping $S_{\mathrm{dw}}$, (c) spectral redistribution of energy by quadruplet wave-wave interactions $S_{\mathrm{nl}}$, (d) wave-induced roughness $Z_{o, w}$, and (e) magnitude of Stokes drift in the fully coupled (FC) simulation at 1300 UTC 7 Oct 2016. (f)-(j) Differences in variables between the FC and no Gulf Stream simulations, where positive indicates larger values in the FC simulation. Axes are as in Fig. 4.

Observations show that under wind sea conditions, the wind stress lies in the direction of the mean wind (Drennan et al. 1999). However, under mixed seas or swell-dominated conditions, swell can steer the wind stress away from the mean wind direction (Collins et al. 2018). In the model setup, wind stress is not permitted to deviate from the mean wind direction. Thus, the wind stress direction is the same between the FC and no GS simulations, though the magnitude of the wind stress differs due to surface wave roughness (Fig. 6). In the no GS simulation, currents were driven by the wind stress, tides, and water level variations associated with storm forcing. Wind stress and surface currents were strongly aligned on the right side of the hurricane, and most closely aligned near the center (Fig. 6a). The largest angles between the currents and the wind stress were $\sim 30^{\circ}$ in the FL quadrant of the hurricane (Fig. 6a). In the rear-left (RL) quadrant, the currents and wind stress
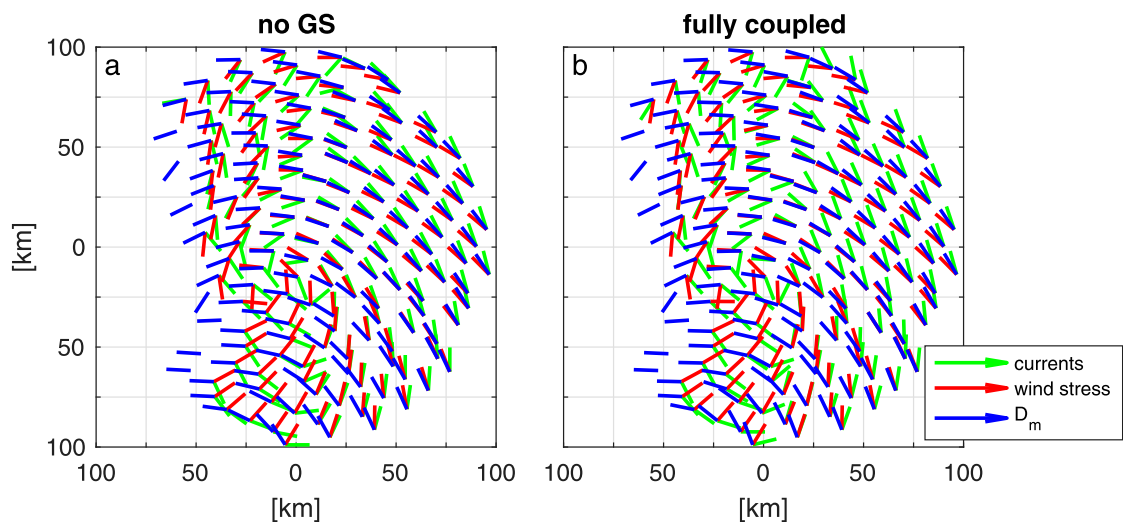

FIG. 6. Wind stress direction, current direction, and mean wave direction $D_{m}$ in the (a) no Gulf Stream (no GS) and (b) fully coupled simulations at 1300 UTC 7 Oct 2016. The polar plots are rotated into the hurricane space, such that $(0,0)$ is the center of the hurricane and the $y$ axis points in the direction of translation of the hurricane. 
were perpendicular. In the no GS simulation, $D_{m}$ was strongly aligned with the wind stress and surface currents in the FR quadrant. In the FL quadrant, $D_{m}$ and surface currents were perpendicular. In the RL quadrant, $D_{m}$ and the surface currents were nearly opposing and the wind stress was perpendicular. The inclusion of the Gulf Stream modifies the direction of the surface currents and, due to refraction in some cases, the mean wave direction (Fig. 6b). In the FR and RR quadrants, the resultant currents from the combination of Gulf Stream and storm-driven currents were more northerly than the storm-driven currents alone, such that the angle between the surface currents and $D_{m}$ was larger, $\sim 45^{\circ}$ in the FR quadrant (Fig. $6 \mathrm{~b}$ ). The Gulf Stream does not influence the direction of the surface currents on the left side of the hurricane. Angles between the surface currents, wind stress, and mean wave direction on the left side of the hurricane are similar in the FC and no GS simulations, though small differences exist and manifest in the evolution of the wave spectra.

\section{b. Spectral effect of wave-current interaction}

Evolution of the frequency spectra and frequencydirectional spectra in the FR and FL quadrants of Hurricane Matthew at 1300 UTC 7 October 2016 reveals the impact of wave-current interaction with Gulf Stream currents on different parts of the wave spectrum. In the FR quadrant, the frequency spectrum evolved differently in the FC and no GS simulations (Fig. 7). As the hurricane approached the location, the peak and mean wave periods both increased in the FC simulation, but the difference between $T_{p}$ and $T_{m}$ became larger, indicating that energy was distributed widely over frequencies during the peak of the storm (Fig. 7a). Compared to the no GS simulation, there was more energy in the spectrum of the FC simulation as the storm approached. At the peak of the storm and afterward, there was less energy in the spectrum of the FC simulation and the energy was contained at a shorter period. The rapid decline in wave energy in the FC simulation compared to the no GS simulation indicates that there might have been refraction away from the location after the peak of the storm, less wave growth due to wind input, or more wave dissipation. We analyze the frequency-directional spectrum in the FR quadrant at the peak of the hurricane (Fig. 8a), associated with the red line in Fig. 7a. The differences between the spectra in the FC and no GS simulations were a function of frequency (Fig. 8b). The shape of the directional spectrum was similar between the simulations, though the total energy was less in the FC simulation (Fig. 8c), consistent with the evolution of the frequency spectrum (Fig. 7) and indicating that refraction
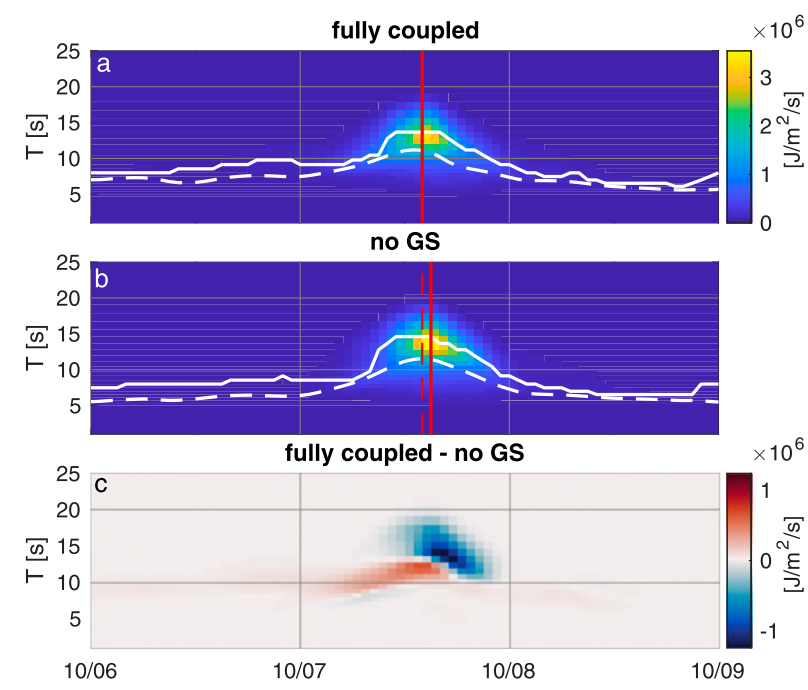

FIG. 7. Evolution of the frequency spectra in the front-right quadrant of the hurricane in the (a) fully coupled (FC) and (b) no Gulf Stream (no GS) simulations during three days of the hurricane's passage through the South Atlantic Bight. In (a) and (b), the solid white lines indicate the peak wave period $T_{p}$ and the dashed white lines indicate the mean wave period $T_{m}$ in each simulation. The red lines indicate the time of maximum spectrally integrated wave energy in each simulation. The dashed red line in (b) indicates the time of maximum spectrally integrated wave energy in the FC simulation. (c) Difference in the frequency spectra between the FC and no GS simulations, where positive indicates more energy in the FC simulation.

over currents was not important at the peak of the hurricane. The peak of the frequency spectrum was shifted to a lower period in the FC simulation, and the spread about $T_{p}$ was smaller (Fig. 8d). At the same location, differences in the frequency-directional distributions of the wave energy source and sink terms between the simulations yield more insight into the effect of the Gulf Stream on wave-current interaction (Fig. 9). Wave growth due to wind input occurred about $T_{p}$ in the FC and no GS simulations, and as such, $S_{\text {in }}$ was maximum at a shorter period in the FC simulation than in the no GS simulation (Figs. 9a,b). There was no difference in the directional distributions of $S_{\text {in }}$ between the FC and no GS simulations. At this location, $S_{\mathrm{dw}}$ was at a maximum at the spectral peak period and direction. The $S_{\mathrm{dw}}$ preferentially dissipated energy at short periods over a wide range of directions (Fig. 9c, note negative values). The $S_{\mathrm{dw}}$ was larger in the FR quadrant in the FC simulation compared to the no GS simulation (Fig. 9d, note negative values). Last, spectral redistribution of energy by nonlinear quadruplet wave-wave interactions preferentially transferred energy from the peak period and direction to longer periods (Fig. 9e). Total $S_{\mathrm{nl}}$ was larger in the FC simulation compared to the no GS simulation. 


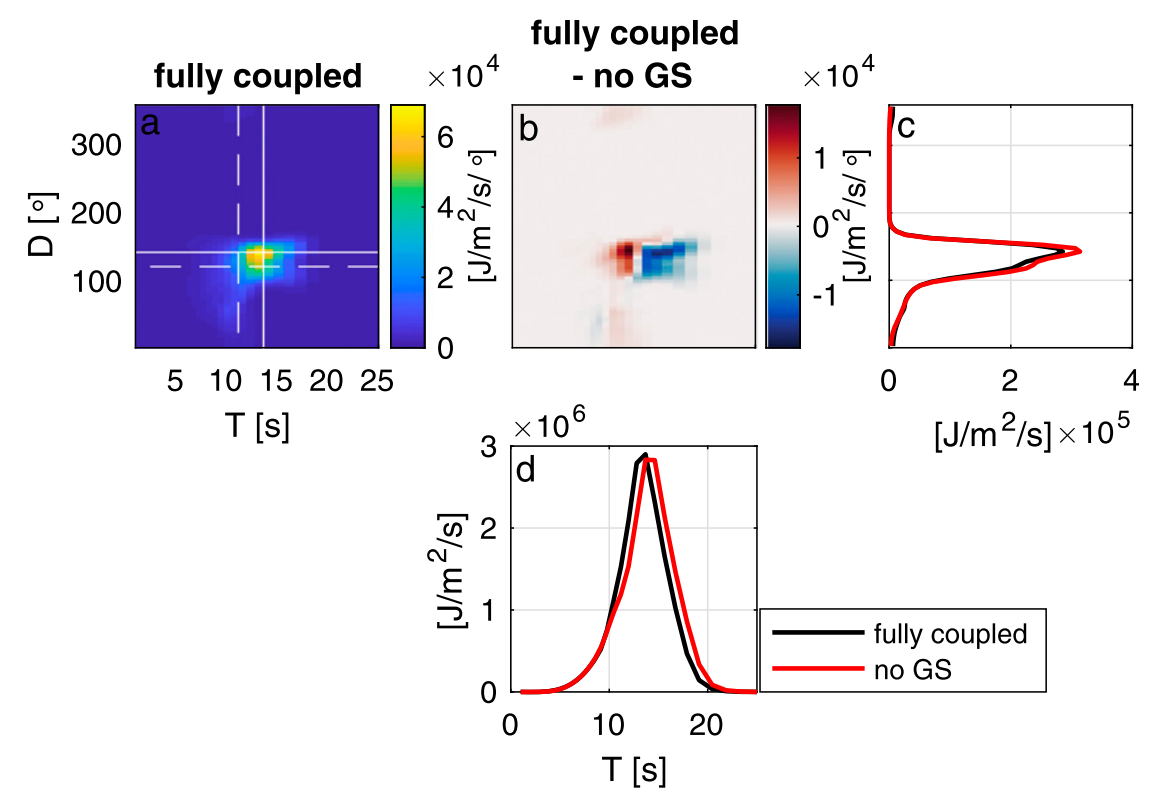

FIG. 8. (a) Frequency-directional spectra in the front-right quadrant of the hurricane at 1300 UTC 7 Oct 2016 in the fully coupled (FC) simulation. (b) Difference in the spectra between the FC and no Gulf Stream (no GS) simulations, where positive indicates more energy in the FC simulation. (c) Directional spectra and (d) frequency spectra in the FC (black) and no GS (red) simulations.

In the FL quadrant of the hurricane, there was little difference in the bulk wave parameters between the FC and no GS simulations (Fig. 4). Nonetheless, the evolution of the frequency spectra and frequency-directional spectra at this location was interesting. As the hurricane approached, there was more wave energy in the spectrum of the FC simulation; however, at the peak of the storm and afterward, there was less wave energy at longer periods (Fig. 10). The directional distribution in the FL quadrant was narrow in both the FC and no GS simulations (Fig. 11c). Total wave energy at the peak wave direction was less in the FC simulation (Fig. 11c), and differences in the spectra between the FC and no GS simulations were largely directionally dependent (Fig. 11b). This indicates that refraction of wave energy might have occurred in the FL quadrant. Though the peak period was the same in the FC and no GS simulations, the frequency distribution in the FC simulation was more peaked (Fig. 11d). All wave energy source and sink terms were larger in magnitude in the FC simulation, but contained directional dependencies. In the no GS simulation, more wave growth due to wind input, dissipation due to whitecapping, and dissipation due to bottom friction occurred in short period waves approaching from $>200^{\circ}$ and long period waves approaching from $<180^{\circ}$ (not shown). The $S_{\mathrm{nl}}$ was small in the FL quadrant at the peak of the hurricane, and differences between the FC and no GS simulations were incoherent within the spectrum (not shown). Differences in the source and sink terms between the simulations were an order of magnitude smaller than those in the FR quadrant.

\section{Discussion}

Assessing the differences between the FC and no GS simulations as a whole allows us to describe how the Gulf Stream influences wave-current interaction beneath the hurricane. In the FR quadrant of the hurricane in the no GS simulation, wind stress, mean wave direction, and currents were in a following wave-current regime, in which waves are lengthened via Doppler shift of the absolute frequency by the components of the currents aligned with the wavenumber vector and the modified dispersion relation. The Gulf Stream modifies the surface currents in the FR quadrant to be more northerly than the storm-driven circulation. As a result, the wave direction, which is closely aligned with the wind stress, and current direction were at a larger angle, reducing wave lengthening by the currents. As a result, waves were steeper and subjected to increased dissipation due to whitecapping and redistribution of energy away from the peak frequency. This also modified surface wave roughness, which impacted wind-driven circulation. In the FL quadrant of the hurricane, stormdriven circulation was negligibly modified by the Gulf 

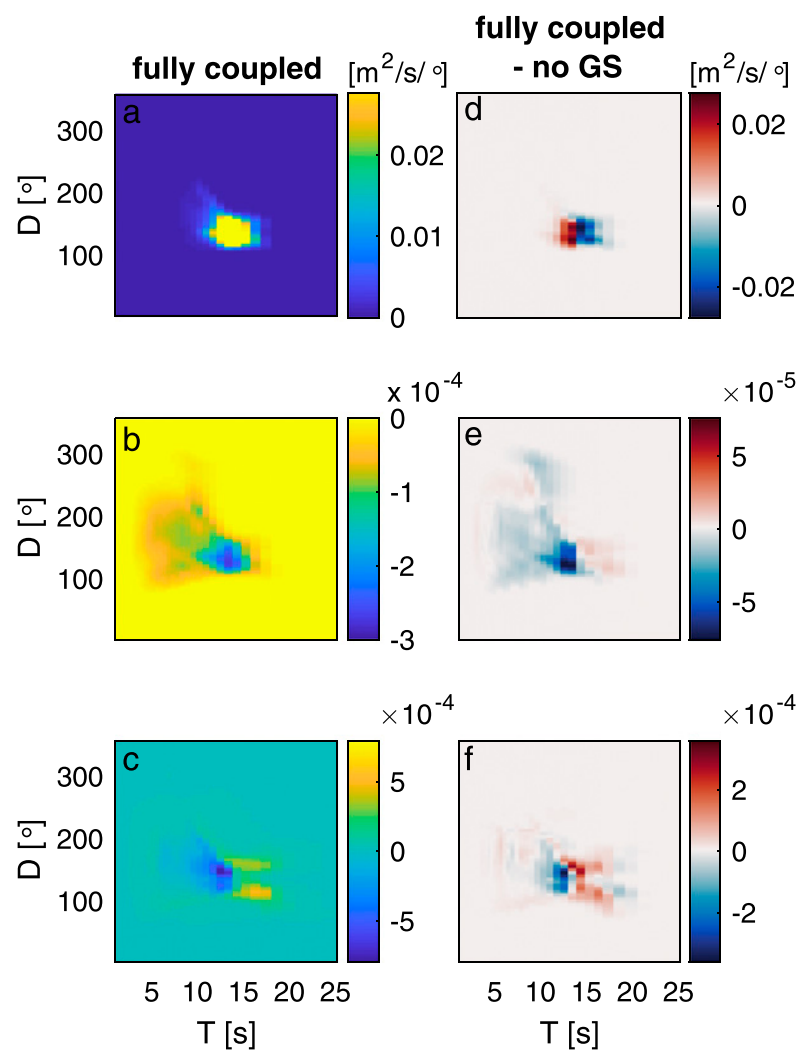

FIG. 9. (a) Wave growth due to wind input $S_{\text {in }}$, (b) dissipation due to whitecapping $S_{\mathrm{dw}}$, and (c) spectral redistribution of energy by quadruplet wave-wave interactions $S_{\mathrm{nl}}$ as functions of period and direction in the front-right quadrant of the hurricane at 1300 UTC 7 Oct 2016 in the fully coupled (FC) simulation. Note that $S_{\text {in }}$ is positive, $S_{\mathrm{dw}}$ is negative, and $S_{\mathrm{nl}}$ can be both positive and negative. (d)-(f) Differences in variables between the FC and no Gulf Stream (GS) simulations.

Stream, and mean wave direction and wind stress were decoupled. Thus, differences in mean wave direction in the FL quadrant between the FC and no GS simulations were a result of refraction of waves exiting gradients in Gulf Stream currents on its western edge and refraction over continental shelf bathymetry.

Observed differences between the FC and no GS simulations were likely also a result of differences in the extended fetch for wave generation induced by the storm-driven circulation and the Gulf Stream under the FR and RR quadrants of the hurricane. To evaluate the potential for differences in the extended fetch between the simulations, we used the criterion proposed by Kudryavstev et al. (2015):

$$
\frac{g r}{u_{r}^{2}} \approx c_{T}\left(\frac{u_{r}}{V}\right)^{1 / q}
$$

where $u_{r}$ is the average maximum wind speed $u$ at radial distance $r$, and $V$ is the translational velocity of the
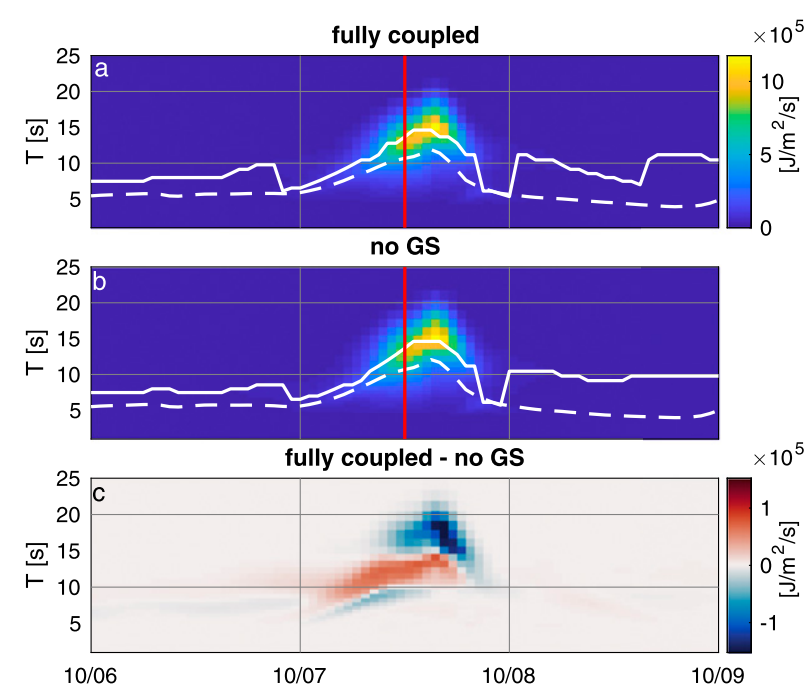

FIG. 10. As in Fig. 7, but in the front-left quadrant of the hurricane.

hurricane. The terms $q$ and $c_{T}$ are constants defined by fetch laws (Kudryavstev et al. 2015). Wind fields were consistent over all model simulations and exhibited asymmetry as a result of hurricane translational velocity and interaction with land. At 1300 UTC 7 October 2016, the hurricane translational velocity was $\sim 9.1 \mathrm{~m} \mathrm{~s}^{-1}$ (HURDAT2; Landsea and Franklin 2013) and the average maximum wind speed was $51.7 \mathrm{~m} \mathrm{~s}^{-1}$ at a radius of $50 \mathrm{~km}$. The effective translational velocity of the hurricane is modified by the underlying currents. In the FC simulation, the translational velocity was reduced by a $2.8 \mathrm{~m} \mathrm{~s}^{-1}$ current and the ratio of the above terms was $\sim 6$. Conditions did not support enhanced wave growth by extended fetch because waves propagated out of the hurricane wind field with increased celerity. In the no GS simulation, the criterion was nearly met (i.e., the ratio is $\sim 1.5$ ), so extended fetch may have been possible. Larger significant wave height, longer peak wave periods, and longer wavelengths would be expected in the no GS simulation as a result of extended fetch. This suggests that the reduction of extended fetch, in addition to wave-current interaction, contributed to the observed influence of the Gulf Stream on Hurricane Matthew wave fields.

We hypothesized that the effect of wave-current interaction over the Gulf Stream on waves and water levels would be local to where the interaction was occurring, and that local wave generation and surge on the shelf would dominate coastal signals. We calculated differences in maximum total water levels at the coast within the SAB between the FC and no GS simulations. Total water levels (TWL) were calculated as

$$
\mathrm{TWL}=R_{2 \%}+T+\mathrm{SS}+\mathrm{SLA},
$$




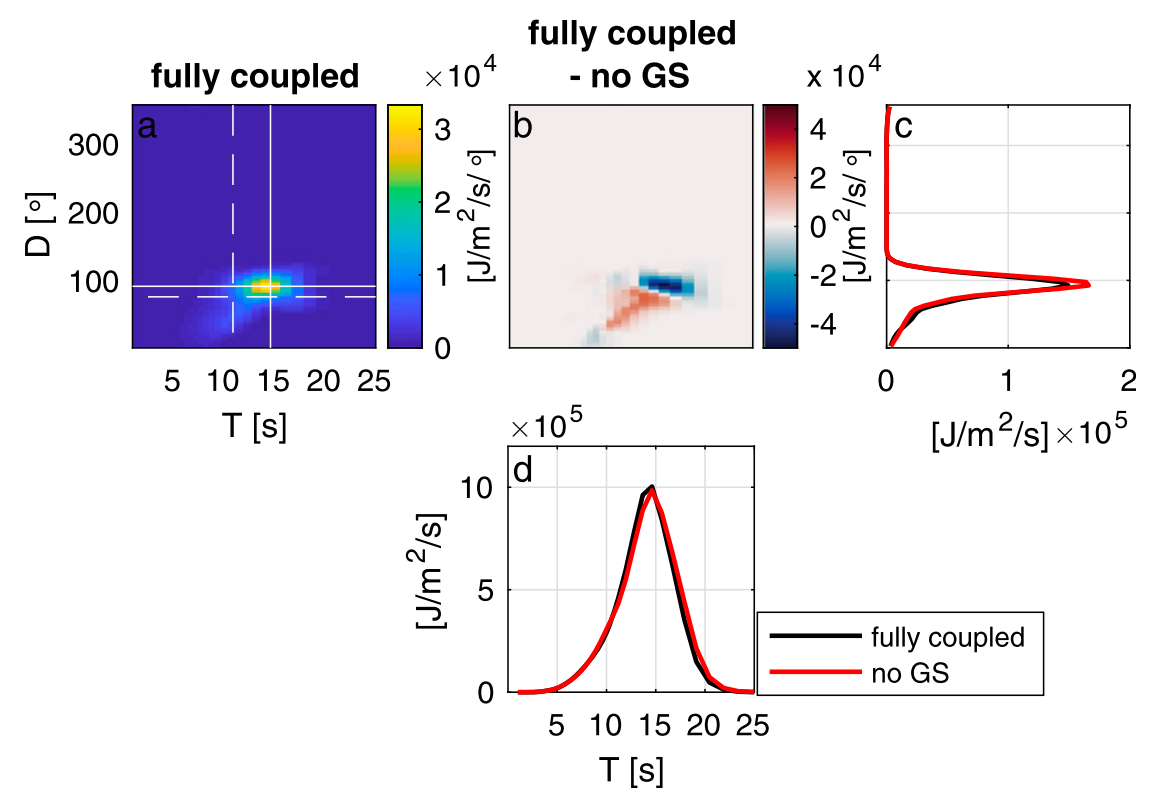

FIG. 11. As in Fig. 8, but in the front-left quadrant of the hurricane.

where $R_{2} \%$ is extreme wave run-up, $T$ is the astronomical tide component of the water level, SS is the storm surge component of the water level, including the inverse barometer effect and wind-driven setup, and SLA is other nontidal sea level anomalies. The term $R_{2} \%$ includes coastal wave setup due to gradients in radiation stress and time-varying swash, and was calculated following the empirical parameterization of Stockdon et al. (2006):

$$
\begin{aligned}
R_{2 \%}= & 1.1\left\{0.35 \beta_{f}\left(H_{0} L_{0}\right)^{1 / 2}\right. \\
& \left.+\frac{\left[H_{0} L_{0}\left(0.563 \beta_{f}^{2}+0.004\right)\right]^{1 / 2}}{2}\right\},
\end{aligned}
$$

where $H_{0}$ is offshore wave height, $L_{0}$ is deep-water wavelength, and $\beta_{f}$ is foreshore beach slope. The terms $H_{0}$ and $L_{0}$ were taken as $H_{s}$ and $L$, respectively, every $\sim 10 \mathrm{~km}$ along the $20-\mathrm{m}$ depth contour in the SAB. We used a uniform $\beta_{f}$ of 0.04 , which is representative of the sandy, dissipative beaches of the SAB. We recognize that shoaling, refraction, and frictional dissipation over bathymetry is not fully resolved given the horizontal resolution of the model.

Spatial variability in maximum TWL through the $\mathrm{SAB}$ is a function of spatially variability in surge and coastal wave energy, related to hurricane intensity and asymmetry, hurricane propagation direction, coastline orientation, and wave transformation over the shelf and currents (Fig. 12b). Maximum TWL were highest at $\sim 5.3 \mathrm{~m}$ at $30^{\circ} \mathrm{N}$ in the $\mathrm{FC}$ simulation (not shown), which is where high water levels were reported during Hurricane Matthew. Differences in maximum TWL between the FC and no GS simulations indicate that wave-current interaction over the Gulf Stream reduced maximum TWL by $0.1-0.2 \mathrm{~m}(5 \%-20 \%)$ in the SAB. Differences in the northern SAB were dominated by differences in wave run-up (Fig. 12b). However, throughout the southern and mid SAB, differences in maximum TWL were mostly driven by lower water levels in the FC simulation (Fig. 12b). There are several explanations for the lower water levels in the FC simulation. The astronomical tides and the inverse barometer effect were identical in both simulations. However, wind-driven setup and SLA differed. Nonlinear interaction between the tide, surge, and waves could further contribute to differences. The geostrophic signature of the Gulf Stream is a barotropic pressure gradient with elevated water levels offshore. When hurricanes track west of the Gulf Stream, as Hurricane Matthew did, winds on the right side of the hurricane are parallel to the Gulf Stream and drive Ekman transport that reinforces the geostrophic pressure gradient (Todd et al. 2018). Alternatively, lower coastal water levels in the FC simulation may be attributed to differences in the wind stress due to surface wave roughness. Though the direction of the wind stress is the same between the FC and no GS simulations, the magnitude is different. Spatially varying, time-integrated wind stress indicates that steeper waves in the FC simulation yielded larger wind stress over the Gulf Stream than in the no 

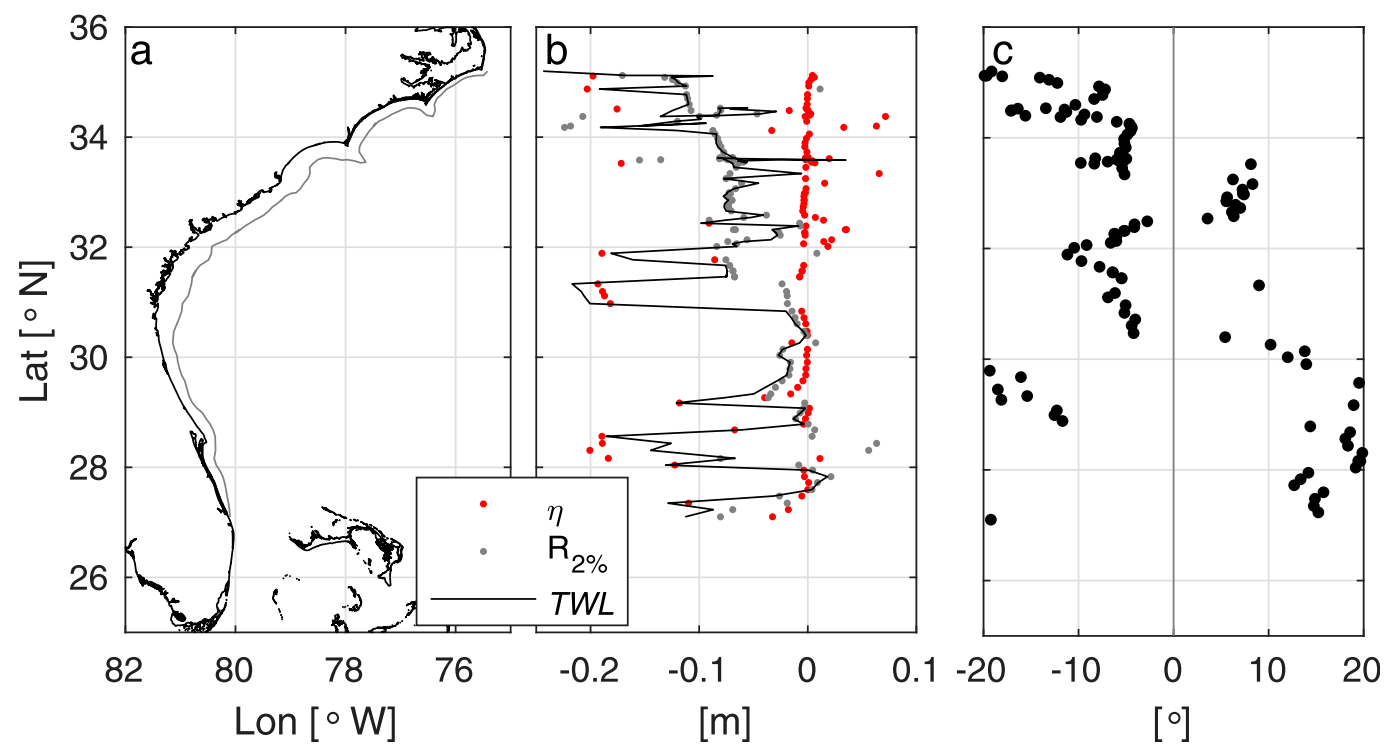

FIG. 12. (a) Coastline of the South Atlantic Bight (SAB) and 20-m depth contour (gray line). (b) Difference in maximum total water level (TWL), wave run-up $\left(R_{2} \%\right)$, and the free surface elevation $(\eta)$ along the 20-m depth contour between the fully coupled (FC) and no Gulf Stream (no GS) simulations over three days of the hurricane's passage through the SAB, where positive indicates higher TWL in the FC simulation. (c) Maximum differences in mean wave direction $D_{m}$ along the 20-m depth contour between the FC and no GS simulations over three days of the hurricane's passage through the SAB. Positive indicates clockwise rotation of $D_{m}$ in the FC simulation relative to the no GS simulation.

GS simulation (not shown). Although the direction of transport associated with the time-integrated wind stress was not analyzed, it is possible that larger wind stress caused greater transport away from the coast. Finally, the magnitude of the Stokes drift was smaller in the FC simulation compared to the no GS simulation, and may have contributed to larger SLA in the no GS simulation.

To further investigate how the effect of wave-current interaction over the Gulf Stream is manifested at the coast, the maximum difference in incident mean wave direction along the 20-m depth contour in the SAB between the FC and no GS simulations was calculated for 6-9 October 2016. Maximum differences in $D_{m}>5^{\circ}$ were resolved by the model (Fig. 12c). The largest maximum differences in $D_{m}$ were $\pm 20^{\circ}$ and indicate that incident waves approached from both more northerly and more southerly directions in the FC simulation depending on the section of the coastline (Fig. 12c). Along the coast of southern Florida, maximum differences in $D_{m}$ were $10^{\circ}-20^{\circ}$ and were associated with refraction of farfield waves generated when the hurricane was south of the Gulf Stream. Similarly, along the northern coast of the $\mathrm{SAB}$, maximum differences in $D_{m}$ were due to refraction of waves when the hurricane was in the southern and central SAB. For the central coast of the SAB, where maximum TWL were large and coastal impacts severe, differences in incident wave directions as a result of wave-current interaction over the Gulf Stream manifested in longshore transport of eroded sediment and evolution of the nearshore poststorm. Inclusion of the Gulf Stream is necessary for accurate prediction of coastal impacts due to hurricanes in the SAB.

\section{Conclusions}

Though previous work has addressed the interaction of far-field hurricane swell with the Gulf Stream in the $\mathrm{SAB}$, understanding of wave-current interaction between complex, rapidly evolving wave fields beneath a hurricane and the Gulf Stream has not been addressed. In this work, we used a coupled ocean-wave model to simulate Hurricane Matthew wave generation, propagation, and dissipation through the South Atlantic Bight with both storm-driven circulation and Gulf Stream currents. The Gulf Stream modified the following wavecurrent regime in the front-right quadrant of the hurricane, reducing wave lengthening and resulting in steeper waves and increased energy dissipation due to whitecapping. The Gulf Stream also decreased the potential for extended fetch for wave generation in the front-right quadrant of the hurricane, reducing wave energy. Effects of wave-current interaction over the Gulf Stream propagated to the coast, where differences in maximum 
TWL were up to $0.2 \mathrm{~m}$ and maximum differences in incident mean wave direction approached $20^{\circ}$. This work establishes that inclusion of the Gulf Stream is necessary for predictions of coastal impacts due to hurricanes.

Acknowledgments. C.A. Hegermiller is grateful to the Woods Hole Oceanographic Institution (WHOI) Postdoctoral Scholarship program and the WHOI-U.S. Geological Survey (USGS) cooperative agreement for support. This project was supported by the USGS Coastal and Marine Hazards and Resources Program and by the Office of Naval Research, Increasing the Fidelity of Morphological Storm Impact Predictions Project. Thank you to the internal and external reviewers for improving the quality of this work, and to conversations within the Woods Hole community during the development of the experiment and analysis of the results. Model data can be found at http://geoport.whoi.edu/ thredds/catalog/sand/usgs/users/chegermiller/projects/ WCI_JPO_2019/catalog.html. Figure color maps are from Thyng et al. (2016).

\section{REFERENCES}

Ardhuin, F., and Coauthors, 2012: Numerical wave modeling in conditions with strong currents: Dissipation, refraction, and relative wind. J. Phys. Oceanogr., 42, 2101-2120, https:// doi.org/10.1175/JPO-D-11-0220.1.

—_, S. T. Gille, D. Menemenlis, C. B. Rocha, N. Rascle, B. Chapron, J. Gula, and J. Molemaker, 2017: Small-scale open ocean currents have large effects on wind wave heights. J. Geophys. Res. Oceans, 122, 4500-4517, https://doi.org/ 10.1002/2016JC012413.

Banihashemi, S., and J. T. Kirby, 2019: Approximation of wave action conservation in vertically sheared mean flows. Ocean Modell., 143, 101460, https://doi.org/10.1016/j.ocemod.2019.101460.

-,- , and Z. Dong, 2017: Approximation of wave action flux velocity in strongly sheared mean flows. Ocean Modell., 116, 33-47, https://doi.org/10.1016/j.ocemod.2017.06.002.

Booij, N., R. C. Ris, and L. H. Holthuijsen, 1999: A thirdgeneration wave model for coastal regions, Part I. Modeling description and validation. J. Geophys. Res., 104, 7649-7666, https://doi.org/10.1029/98JC02622.

Bowyer, P. J., and A. W. MacAfee, 2005: The theory of trapped-fetch waves with tropical cyclones-An operational prospective. Wea. Forecasting, 20, 229-244, https://doi.org/10.1175/WAF849.1.

Charnock, H., 1955: Wind stress on a water surface. Quart. J. Roy. Meteor. Soc., 81, 639, https://doi.org/10.1002/qj.49708135027.

Chen, X., I. Ginis, and T. Hara, 2018: Sensitivity of offshore tropical cyclone wave simulations to spatial resolution in wave models. J. Mar. Sci. Eng., 6, 116, https://doi.org/10.3390/jmse6040116

Collins, C. O., III, H. Potter, B. Lund, H. Tamura, and H. C. Graber, 2018: Directional wave spectra observed during intense tropical cyclones. J. Geophys. Res. Oceans, 123, 773-793, https://doi.org/10.1002/2017JC012943.

Davis, C., and Coauthors, 2008: Prediction of landfalling hurricanes with the advanced hurricane WRF model. Mon. Wea. Rev., 136, 1990-2005, https://doi.org/10.1175/2007MWR2085.1
Donelan, M. A., B. K. Haus, N. Reul, W. J. Plant, M. Stiassnie, H. C. Graber, O. B. Brown, and E. S. Saltzman, 2004: On the limiting aerodynamic roughness of the ocean in very strong winds. Geophys. Res. Lett., 31, L18306, https://doi.org/10.1029/ 2004GL019460.

Doyle, J. D., and Coauthors, 2014: Tropical cyclone prediction using COAMPS-TC. Oceanography, 27 (3), 104-115, https:// doi.org/10.5670/oceanog.2014.72.

Drennan, W. M., K. K. Kahma, and M. A. Donelan, 1999: On momentum flux and velocity spectra over waves. Bound.-Layer Meteor., 92, 489, https://doi.org/10.1023/A:1002054820455.

- H. C. Graber, D. Hauser, and C. Quentin, 2003: On the wave age dependence of wind stress over pure wind seas. J. Geophys. Res., 108, 8062, https://doi.org/10.1029/2000JC000715.

_, P. K. Taylor, and M. J. Yelland, 2005: Parameterizing the sea surface roughness. J. Phys. Oceanogr., 35, 835-848, https:// doi.org/10.1175/JPO2704.1.

Egbert, G. D., and S. Y. Erofeeva, 2002: Efficient inverse modeling of barotropic ocean tides. J. Atmos. Oceanic Technol., 19, 183-204, https://doi.org/10.1175/1520-0426(2002)019<0183: EIMOBO $>2.0 . \mathrm{CO} ; 2$.

Ezer, T., L. P. Atkinson, and R. Tuleya, 2017: Observations and operational model simulations reveal the impact of Hurricane Matthew (2016) on the Gulf Stream and coastal sea level. Dyn. Atmos. Oceans, 80, 124-138, https://doi.org/10.1016/ j.dynatmoce.2017.10.006.

Fairall, C. W., E. F. Bradley, D. P. Rogers, J. B. Edson, and G. S. Young, 1996: Bulk parameterization of air-sea fluxes in TOGA COARE. J. Geophys. Res., 101, 3747-3767, https:// doi.org/10.1029/95JC03205.

,,- J. E. Hare, A. A. Grachev, and J. B. Edson, 2003: Bulk parameterization of air-sea fluxes: Updates and verification for the COARE algorithm. J. Climate, 16, 571-591, https:// doi.org/10.1175/1520-0442(2003)016<0571:BPOASF $>2.0 . C O ; 2$.

Fan, Y., I. Ginis, T. Hara, C. W. Wright, and E. J. Walsh, 2009: Numerical simulations and observations of surface wave fields under extreme tropical cyclone. J. Phys. Oceanogr., 39, 20972116, https://doi.org/10.1175/2009JPO4224.1.

Haidvogel, D. B., and Coauthors, 2008: Ocean forecasting in terrain-following coordinates: Formulation and skill assessment of the Regional Ocean Modeling System J. Comput. Phys., 227, 3595-3624, https://doi.org/10.1016/j.jcp.2007.06.016.

-, H. G. Arango, K. Hedstrom, A. Beckmann, P. MalanotteRizzoli, and A. F. Shchepetkin, 2000: Model evaluation experiments in the North Atlantic Basin: Simulations in nonlinear terrain-following coordinates. Dyn. Atmos. Oceans, 32, 239-281, https://doi.org/10.1016/S0377-0265(00)00049-X.

Hasselmann, K., and Coauthors, 1973: Measurements of windwave growth and swell decay during the Joint North Sea Wave Project (JONSWAP). Dtsch. Hydrogr. Z., A8 (12), 93 pp.

Holthuijsen, L. H., and H. L. Tolman, 1991: Effects of the Gulf Stream of ocean waves. J. Geophys. Res., 96, 12 755-12 771, https://doi.org/10.1029/91JC00901.

— M. D. Powell, and J. D. Pietrzak, 2012: Wind and waves in extreme hurricanes. J. Geophys. Res., 117, C09003, https:// doi.org/10.1029/2012JC007983.

Kantha, L. H., and C. A. Clayson, 1994: An improved mixed layer model for geophysical applications. J. Geophys. Res., 99, $25235-25266$.

Kirby, J. T., and T. M. Chen, 1989: Surface waves on vertically sheared flows: approximate dispersion relations. J. Geophys. Res., 94, 1013-1027, https://doi.org/10.1029/ JC094iC01p01013. 
Komen, G. J., S. Hasselmann, and K. Hasselmann, 1984: On the existence of a fully developed wind-sea spectrum. J. Phys. Oceanogr., 14, 1271-1285, https://doi.org/10.1175/ 1520-0485(1984)014<1271:OTEOAF > 2.0.CO;2.

Kudryavstev, V. N., S. A. Grodsky, V. A. Dulov, and A. N. Bol'shakov, 1995: Observations of wind waves in the Gulf Stream frontal zone. J. Geophys. Res., 100, 20 715- 20727 , https://doi.org/10.1029/95JC00425.

Kudryavstev, V., P. Golubkin, and B. Chapron, 2015: A simplified wave enhancement criterion for moving extreme events. J. Geophys. Res. Oceans, 120, 7538-7558, https://doi.org/ 10.1002/2015JC011284.

Kumar, N., G. Voulgaris, J. C. Warner, and M. Olabarrieta, 2012: Implementation of the vortex force formalism in the coupled ocean-atmosphere-wave-sediment transport (COAWST) modeling system for inner shelf and surf zone applications. Ocean Modell., 47, 65-95, https://doi.org/10.1016/j.ocemod.2012.01.003.

Landsea, C. W., and J. L. Franklin, 2013: Atlantic hurricane database uncertainty and presentation of a new database format. Mon. Wea. Rev., 141, 3576-3592, https://doi.org/10.1175/ MWR-D-12-00254.1.

Moon, I. J., I. Ginis, T. Hara, H. L. Tolman, C. W. Wright, and E. J. Walsh, 2003: Numerical simulation of sea surface directional wave spectra under hurricane wind forcing. J. Phys. Oceanogr., 33, 1680-1706, https://doi.org/10.1175/2410.1.

Olabarrieta, M., J. C. Warner, B. Armstrong, J. B. Zambon, and R. He, 2012: Ocean-atmosphere dynamics during Hurricane Ida and Nor'Ida: An application of the coupled oceanatmosphere-wave-sediment transport (COAWST) modeling system. Ocean Modell., 43-44, 112-137, https://doi.org/ 10.1016/j.ocemod.2011.12.008.

_ W. R. Geyer, and N. Kumar, 2014: The role of morphology and wave-current interaction at tidal inlets: An idealized modeling analysis. J. Geophys. Res. Oceans, 119, 8818-8837, https://doi.org/10.1002/2014JC010191.

Oost, W. A., G. J. Komen, C. M. J. Jacobs, and C. van Oort, 2002: New evidence for a relation between wind stress and wave age from measurements during ASGAMAGE. Bound-Layer Meteor., 103, 409-438, https://doi.org/10.1023/A:1014913624535.

Orescanin, M., B. Raubenheimer, and S. Elgar, 2014: Observations of wave effects on inlet circulation. Cont. Shelf Res., 82, 37-42, https://doi.org/10.1016/j.csr.2014.04.010.

Powell, M. D., P. J. Vickery, and T. A. Reinhold, 2003: Reduced drag coefficient for high wind speeds in tropical cyclones. Nature, 422, 279-283, https://doi.org/10.1038/nature01481.

Rapizo, H., A. V. Babanin, D. Provis, and W. E. Rogers, 2017: Current-induced dissipation in spectral wave models. J. Geophys. Res. Oceans, 122, 2205-2225, https://doi.org/10.1002/2016JC012367.

— - T. H. Durrant, and A. V. Babanin, 2018: An assessment of the impact of surface currents on wave modeling in the Southern Ocean. Ocean Dyn., 68, 939-955, https://doi.org/ 10.1007/s10236-018-1171-7.

Shchepetkin, A. F., and J. C. McWilliams, 2005: The Regional Ocean Modeling System (ROMS): A split-explicit, free-surface, topography-following-coordinates ocean model. Ocean Modell., 9, 347-404, https://doi.org/10.1016/j.ocemod.2004.08.002.

Stockdon, H. F., R. A. Holman, P. A. Howd, and A. H. Sallenger, 2006: Empirical parameterization of setup, swash, and runup. Coastal Eng., 53, 573-588, https://doi.org/10.1016/ j.coastaleng.2005.12.005.

SWAN Team, 2019: SWAN Scientific and Technical Documentation. Delft University of Technology, http:// swanmodel.sourceforge.net/online_doc/swantech/swantech.html.
Taylor, P. K., and M. J. Yelland, 2001: The dependence of the sea surface roughness on the height and steepness of the waves. J. Phys. Oceanogr., 31, 572-590, https://doi.org/10.1175/ 1520-0485(2001)031<0572:TDOSSR > 2.0.CO;2.

Thyng, K. M., C. A. Greene, R. D. Hetland, H. M. Zimmerle, and S. F. DiMarco, 2016: True colors of oceanography: Guidelines for effective and accurate colormap selection. Oceanography, 29 (3), 9-13, https://doi.org/10.5670/oceanog.2016.66.

Todd, R. E., T. G. Asher, J. Heiderich, J. M. Bane, and R. A. Luettich, 2018: Transient response of the Gulf Stream to multiple hurricanes in 2017. Geophys. Res. Lett., 45, 10509 10 519, https://doi.org/10.1029/2018GL079180.

Uchiyama, Y., J. C. McWilliams, and A. F. Shchepetkin, 2010: Wave-current interaction in an oceanic circulation model with a vortex force formalism: Application to the surf zone. Ocean Modell., 34, 16-35, https://doi.org/10.1016/ j.ocemod.2010.04.002.

Wandres, M., E. M. S. Wijeratne, S. Cosoli, and C. Pattiaratchi, 2017: The effect of the Leeuwin Current on offshore surface gravity waves in southwest Western Australia. J. Geophys. Res. Oceans, 122, 9047-9067, https://doi.org/10.1002/2017JC013006.

Warner, J. C., C. R. Sherwood, H. G. Arango, and R. P. Signell, 2005: Performance of four turbulence closure models implemented using a generic length scale method. Ocean Modell., 8, 81-113, https://doi.org/10.1016/j.ocemod.2003.12.003.

,,- R. P. Signell, C. K. Harris, and H. G. Arango, 2008: Development of a three-dimensional, regional, coupled wave, current, and sediment-transport model. Comput. Geosci., 34, 1284-1306, https://doi.org/10.1016/j.cageo.2008.02.012.

_ B. Armstrong, R. He, and J. Zambon, 2010: Development of a coupled ocean-atmosphere-wave-sediment transport (COAWST) modeling system. Ocean Modell., 35, 230-244, https://doi.org/10.1016/j.ocemod.2010.07.010.

— W. C. Schwab, J. H. List, I. Safak, M. Liste, and W. Baldwin, 2017: Inner-shelf ocean dynamics and seafloor morphologic changes during Hurricane Sandy. Cont. Shelf Res., 138, 1-18, https://doi.org/10.1016/j.csr.2017.02.003.

_- , and Coauthors, 2019: A Coupled-Ocean-AtmosphereWave Sediment Transport Numerical Modeling System (COAWST). USGS Github Code Repository, https:// doi.org/10.5066/P9NQUAOW.

White, B. S., and B. Fornberg, 1998: On the chance of freak waves at sea. J. Fluid Mech., https://doi.org/10.1017/ s0022112097007751.

Young, I. R., 2003: A review of the sea state generated by hurricanes. Mar. Structures, 16, 201-218, https://doi.org/10.1016/ S0951-8339(02)00054-0.

Zambon, J. B., R. He, and J. C. Warner, 2014a: Investigation of hurricane Ivan using the coupled ocean-atmosphere-wavesediment transport (COAWST) model. Ocean Dyn., 64, 1535, https://doi.org/10.1007/s10236-014-0777-7.

,$- \ldots$, and $-2014 \mathrm{~b}$ : Tropical to extratropical: Marine environmental changes associated with Superstorm Sandy prior to its landfall. Geophys. Res. Lett., 41, 8935-8943, https:// doi.org/10.1002/2014GL061357

Zang, Z., Z. G. Xue, S. Bao, Q. Chen, N. D. Walker, A. S. Haag, Q. Ge, and Z. Yao, 2018: Numerical study of sediment dynamics during hurricane Gustav. Ocean Modell., 126, 29-42, https://doi.org/10.1016/j.ocemod.2018.04.002.

Zippel, S., and J. Thomson, 2015: Wave breaking and turbulence at a tidal inlet. J. Geophys. Res. Oceans, 120, 1016-1031, https:// doi.org/10.1002/2014JC010025. 